\title{
A Review of Helium-Hydrogen Synergistic Effects in Radiation Damage Observed in Fusion Energy Steels and an Interaction Model to Guide Future Understanding
}

\author{
Jaime Marian ${ }^{\mathrm{a}, \mathrm{b}, 1}$, Tuan Hoang ${ }^{\mathrm{b}, \mathrm{c}}$, Michael Fluss ${ }^{\mathrm{b}}$, Luke L. Hsiung ${ }^{\mathrm{b}}$ \\ ${ }^{a}$ University of California Los Angeles, Los Angeles, CA 90095 \\ ${ }^{\mathrm{b}}$ Lawrence Livermore National Laboratory, Livermore, CA 94551 \\ ${ }^{\mathrm{C}}$ University of California at Berkeley, Berkeley, CA 94720
}

\begin{abstract}
Under fusion reactor conditions, large quantities of irradiation defects and transmutation gases are produced per unit time by neutrons, resulting in accelerated degradation of structural candidate ferritic (F) and ferritic/martensitic (F/M) steels. Due to the lack of a suitable fusion neutron testing facility, we must rely on high-dose-rate ion-beam experiments and present day crude modeling estimates. Of particular interest is the possibility of synergistic (positive feedback) effects on materials properties due to the simultaneous action of $\mathrm{He}, \mathrm{H}$, and displacement damage (dpa) during operation. In this paper we discuss the state-of-the-art in terms of the experimental understanding of synergistic effects and carry out simulations of triple-species irradiation under ion-beam conditions using first-of-its-kind modeling techniques. Although, state-of-the-art modeling and simulation is not sufficiently well developed to shed light on the experimental uncertainties, we are able to conclude that it is not clear whether synergistic effects, which are experimentally seen to exist, will ultimately play a critical role in material performance under fusion energy conditions. We review here some of the evidence for the synergistic effects of hydrogen in the presence of helium and displacement damage, and also include some recent data from our research. While the experimental results to date suggest possible mechanisms for the observed synergistic effects, it is only with more advanced modeling that we can hope to understand the details underlying the experimental observations. By employing modeling and simulation we propose an interaction model that is qualitatively consistent with experimental observations of $\mathrm{dpa} / \mathrm{He} / \mathrm{H}$ irradiation behavior. Our modeling, the results of which should be helpful to researchers going forward, points to gaps and voids in the current understanding of triple ion-beam irradiation effects (displacement damage produced simultaneously with helium and hydrogen implantation) and the synergistic effects of hydrogen.
\end{abstract}

\footnotetext{
${ }^{1}$ Corresponding author. Email: jmarian@ucla.edu
}

Ph number: (310) 2069161 


\section{Introduction: Fusion structural materials}

A scientific challenge for fusion energy is to develop an understanding of the response to radiation damage accumulation of the first wall and breeding-blanket materials that will likely determine the operating parameters and hence the energy efficiency (operating temperature) and overall lifetime of a fusion reactor. The structural materials of a fusion reactor are exposed to a hard neutron spectrum including the $14 \mathrm{MeV}$ neutrons from deuterium-tritium fusion that result in atomic displacement cascades and transmutation nuclear reactions. The displacement cascades produce vacancies, interstitials, and a variety of extended defects, but of particular concern is the simultaneous production of helium and hydrogen at dose rates and accumulated concentrations for which the materials and engineering communities have little practical experience and hence, little understanding.

Neutron irradiation conditions in a fusion power reactor are expected to be 1.0 to $1.15 \times 10^{15}$ $\mathrm{n} / \mathrm{cm}^{2} \mathrm{~s}$. This represents a neutron wall-loading of 2-3 MW/m $\mathrm{m}^{2}$, an integrated wall load of 1.0-1.5 $\mathrm{MWy} / \mathrm{m}^{2}$, a surface heat load of $0.1-1.0 \mathrm{MW} / \mathrm{m}^{2}$ and a volume power density of $20-30 \mathrm{~W} / \mathrm{cm}^{3}[1]$. The nominal neutron flux in the equatorial plane of DEMO is shown in Figure 1.

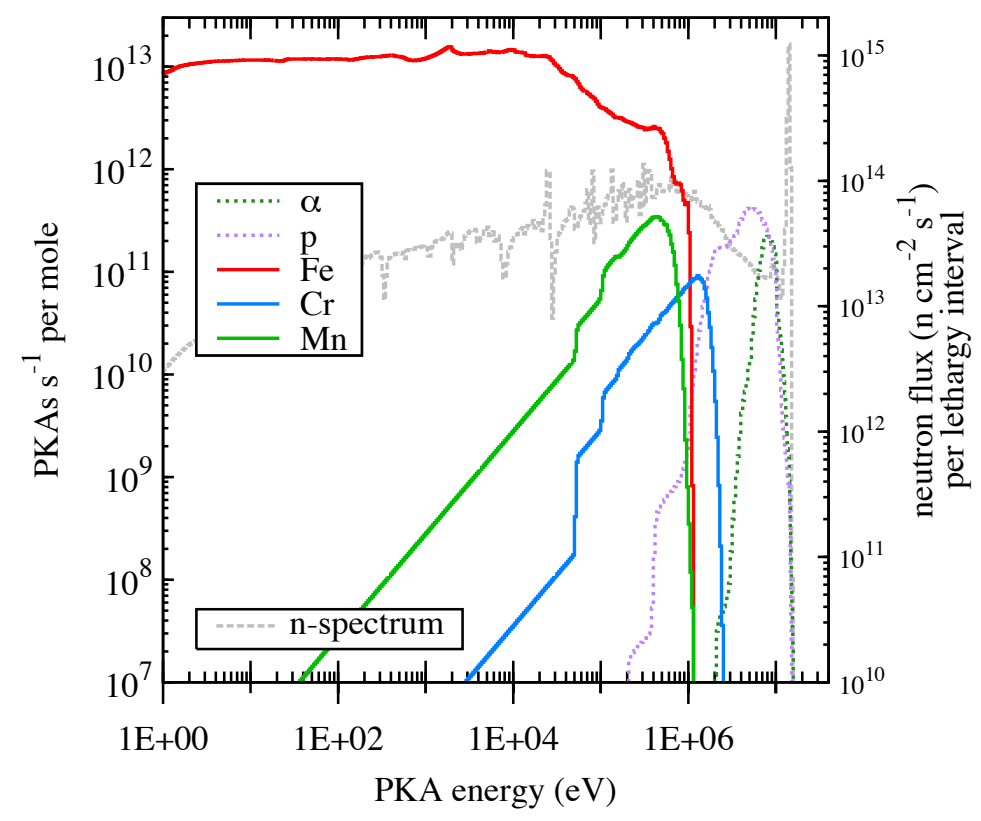

Figure 1: Neutron, $\mathrm{He}, \mathrm{H}$, and primary knock-on atom (PKA) spectrum for a number of selected species for DEMO fusion irradiation conditions [2]

Structural materials for fusion energy utilize an elemental composition that emphasizes low activation ( $\mathrm{Fe}, \mathrm{Cr}, \mathrm{V}, \mathrm{Ti}, \mathrm{W}, \mathrm{Si}, \mathrm{C}, \mathrm{Ta})$ [3]. While vanadium alloys, tungsten alloys and the $\mathrm{SiC} / \mathrm{SiC}$ fiber-reinforced ceramic composites are potential advanced candidate materials, the reduced activation ferritic/martensitic (RAFM) steels are currently the most promising class of alloys for early fusion applications because of their degree of technological development and a history of industrial experience [4]. Ferritic/martensitic steels are all much more resistant to void swelling than are austenitic steels. The maximum swelling rate $(\sim 0.1 \% / \mathrm{dpa})$ is always lower than that for austenitic steels $(>1 \% / \mathrm{dpa})$ and the swelling rate and peak swelling temperatures $\left(\sim 420^{\circ} \mathrm{C}\right)$ are both relatively insensitive to chromium content below $\sim 10 \%$ concentration. The chromium in solid solution is not primarily responsible for the swelling resistance of $\mathrm{F} / \mathrm{M}$ steels: that resistance is probably an intrinsic property similar to that of pure $\alpha-\mathrm{Fe}$ [5]. For more details 
on the current state-of-the-art regarding $\mathrm{He}$ and $\mathrm{H}$ effects on fusion materials, we refer the reader to the overview by Zinkle et al [6].

\section{Displacement damage and the generation of $\mathrm{He}$ and $\mathrm{H}$}

The rate of atomic displacements per atom (dpa) will amount to 20-30 dpa/year in steels, while the $\mathrm{He}$ and $\mathrm{H}$ gas produced by transmutation nuclear reactions will be $10-15$ appm and 40-50 appm per dpa respectively, all of which are produced continuously and simultaneously. There is considerable experience, both experimental and modeling, for low dpa production simultaneously with $\mathrm{He}$ that is relevant to fission reactors, but in fusion reactors not only are the dpa and He rates one to two orders of magnitude greater but the simultaneous transmutation production of $\mathrm{H}$ introduces a new variable for which little experimental data and modeling exist.

\subsection{Transmutation production of gas atoms}

Nuclear reactions $(n, \alpha),(n, p)$, and $(2 n, p)$ from neutrons result in the transmutation production of the gas atoms helium $(\mathrm{He})$ and hydrogen $(\mathrm{H})$, which, while rare compared to $(\mathrm{n}, \gamma)$, can result in deleterious material property changes. In a comparison of a fission reactor neutron spectrum and a computed DEMO neutron spectrum it is observed that the fluxes per lethargy unit are greater for the fusion spectrum at all energies above $2 \mathrm{MeV}$ [7]. It is noted in [8] that because of inadequacy of the modeling of the DEMO spectrum, the fusion flux below $2 \mathrm{MeV}$ may also be greater than the fission spectrum. Moreover because every fusion reaction yields a $14.1 \mathrm{MeV}$ neutron there is a peak in the neutron spectrum at that energy.

Despite belief to the contrary, experimental research has discovered the production and retention of $\mathrm{H}$ in combination with $\mathrm{He}$ in fission reactor fcc austenitic steels [9]: this being surprising evidence for the synergistic consequences of simultaneous $\mathrm{H}$ and $\mathrm{He}$ production along with displacement damage in a fission reactor environment. While this discovery identified interesting degradation of the irradiated steels associated with the synergy of $\mathrm{H}$ and $\mathrm{He}$, in fusion the consequences of transmutation gas production have the potential to result in more serious problems because of the much higher production rates and the much greater lifetime doses.

\section{Effect on mechanical properties}

The evolving microstructure of materials irradiated in a fusion reactor environment is a result of the cumulative effects of a continually produced population of atomic displacements from radiation cascades, the production of transmutants; particularly $\mathrm{He}$ and $\mathrm{H}$, and the effects of temperature on mass transport and annealing of defects. The evolving defect structure will consist of the steady state population of point defects, small defect clusters, dislocation loops, precipitates, stacking-fault tetrahedra, helium and helium hydrogen bubbles, ballistic decomposition and mixing of second phases, and voids to name just a few. The microstructure associated with hydrogen is not currently known, but as we will discuss later, there do appear to be synergistic effects due to hydrogen interacting with the already complex and dynamically evolving microstructure just described. The physical and mechanical properties of the irradiated materials are a direct consequence of this evolving microstructure. Examples include: hardening, loss of ductility, fracture toughness and creep strength, as well as macroscopic swelling of the material. Again, see reviews for more details [10].

\section{Experimental evidence for He-H synergies:}

In a 1994 report to General Atomics, Bullough reviewed the current understanding of possible radiation effects in vanadium alloy and in the ferritic-martensitic (F/M) steel 9Cr-1Mo known as T91 (also P91) [1]. It was noted that dual ion-beam data on pure vanadium shows evidence for both helium and hydrogen leading to significant swelling in pure vanadium in the presence of simultaneous production of atomic displacement damage from heavy ion irradiation [11]. It is 
emphasized in this report that an important issue for the application of $\mathrm{F} / \mathrm{M}$ steel as the fusion first wall material was, and still is today, "resistance to irradiation damage in the presence of the helium and hydrogen that will be produced by the high-energy fusion neutrons." While the development of core materials for fast fission reactors benefited from the availability of testing reactors, no such facilities exist today for the development of fusion materials. This then leaves us with a strategy of accumulating data from simulation experiments that inform and are understood through coupling to computational models. Unfortunately, this approach is not without uncertainties arising from unexpected phenomena or from the difference between the simulation conditions and those of an actual fusion facility; dose rate, details of the damage cascade arising from the kinetics of the cascade inducing particle, specimen dimensions, and details of the chemistry, phase and microstructural features of the material under test. An early suggestion for a $\mathrm{He}$ and $\mathrm{H}$ synergy in the presence of displacement damage in $\mathrm{F} / \mathrm{M}$ steel (1986) was given by Farrell and Lee [12] who investigated the combined effects of the high input of helium and hydrogen along with displacement damage using multiple simultaneous ion beams (MSIB) of He, $\mathrm{D}$, and $\mathrm{Fe}$ and reported a rather significant increase in the peak swelling rate in $12 \mathrm{Cr}-1 \mathrm{Mo}$ steel.

It is useful to note that while the primary motive for understanding the synergistic role of displacement damage and helium and hydrogen production in $\mathrm{F} / \mathrm{M}$ steels comes from a need to identify radiation tolerant materials for fusion energy, this same challenge became a research issue for fission energy austenitic steels when it was suggested that hydrogen might serve the same role as helium in stabilizing small vacancy clusters to form bubbles that once reaching critical size lead to void formation [13]. Because hydrogen is a fast diffuser, it was commonly held that in austenitic (stainless) steels it could not be retained at high concentrations and would diffuse out. Experimental work led to the discovery that hydrogen, which is produced by nuclear reactions but which is also introduced into steels by a variety of other processes both nuclear and chemical, is retained when helium nucleated cavities become a significant part of the microstructure [14].

\subsection{Multiple Simultaneous Ion Beam Experiments (MSIB)}

Ion beams provide an experimental platform for exploring and understanding the mechanisms of radiation damage accumulation. Hundreds of displacements per atom can be accumulated in a small target material in a matter of hours, temperatures are easily controlled by monitoring the surface temperature of the material under irradiation, and the role of transmutants associated with neutron nuclear reactions can be simulated by co-implantation simultaneously with the heavy-ion used for producing the displacement damage. This said, it is not possible to simply utilize the integral dpa as a yardstick for comparison with neutron-environment experiments. Methods for accounting for the two to three orders of magnitude difference in displacement rates and helium and hydrogen implantation rates are only now being developed [15]. Because specimen sizes and irradiated depths are typically small for MSIB $\left(100 \mathrm{~mm}^{2}\right.$ and 1 to $10 \mu \mathrm{m}$ respectively) when compared to reactor irradiations on much larger specimens, many types of post irradiation mechanical diagnostics are challenging and thus must be performed at the micron scale.

\subsubsection{Experimental descriptions of $\mathrm{He}$ and $\mathrm{H}$ synergy effects}

The work of Farrell and Lee [12] provides evidence for a hydrogen and helium synergy. In their work TEM observation of bubbles and voids from dual-beam $(\mathrm{Fe}+\mathrm{He})$ and triple-beam irradiations $(\mathrm{Fe}+\mathrm{He}+\mathrm{D})(100 \mathrm{dpa}$ from $\mathrm{Fe}-i o n s, 10 \mathrm{appm} \mathrm{He} / \mathrm{dpa}$ and $40 \mathrm{appm} \mathrm{D/dpa)} \mathrm{suggest} \mathrm{that}$ the presence of deuterium increased the nucleation of helium bubbles compared with the dual beam irradiation, decreasing bubble size but increasing bubble density. Considering the measured trapping enthalpy of deuterium at 1-nm helium bubbles in iron $(0.75 \mathrm{eV})$ [16], it is conjectured that deuterium in someway reduces the bubble surface energy allowing for more helium bubble formation. Because there are more bubbles, bubble growth is reduced and hence void growth is delayed. However, no determination of the critical cavity size for biased driven cavity growth 
was determined in these experiments. A reduction in the critical radius associated with mixed D and $\mathrm{He}$ bubbles could result in an early onset of bias driven cavity growth. Such a scenario might

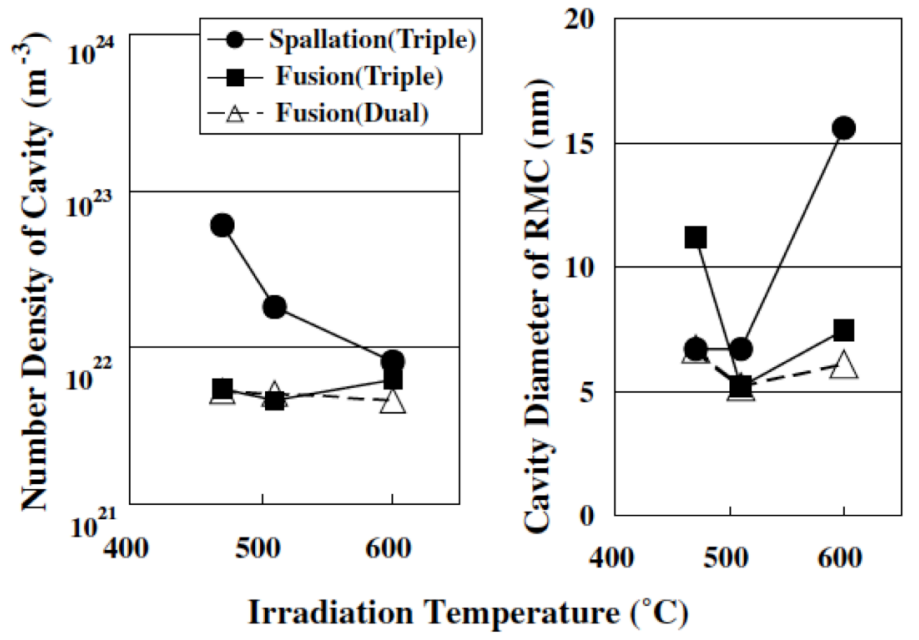

Figure 2 The number density and diameter of root mean cube of cavities formed in F82H steel irradiated by three beam conditions. From figure 4 in ref. [18].

be important in F/M steels with dispersed nano-particles (ODS steel) where nucleation at nanoparticle sites dominates.

It is worthwhile to consider the series of MSIB triple beam experiments led by Eiichi Wakai that were reported over the period from 2003 to 2009 making use of the Tagasaki TIARA MSIB triple beam facility at the JAEA laboratory at Tokai, Naka, Ibaraki, Japan [17, 18, 19, 20, 21, 22]. While a complete review of these experiments is beyond the scope of this paper, a summary that highlights some of the important results can serve as a pedagogical outline for future experiments and as a motivation for future computational modeling of the helium and hydrogen synergy in the presence of atomic displacements. Our focus in this summary will be the observations of bubble and void formation for which we have developed appropriate modeling that we report further on in this paper.

In the work reported in $[17,18], \mathrm{F} 82 \mathrm{H}$, a RAFM steel candidate material for fusion energy, is

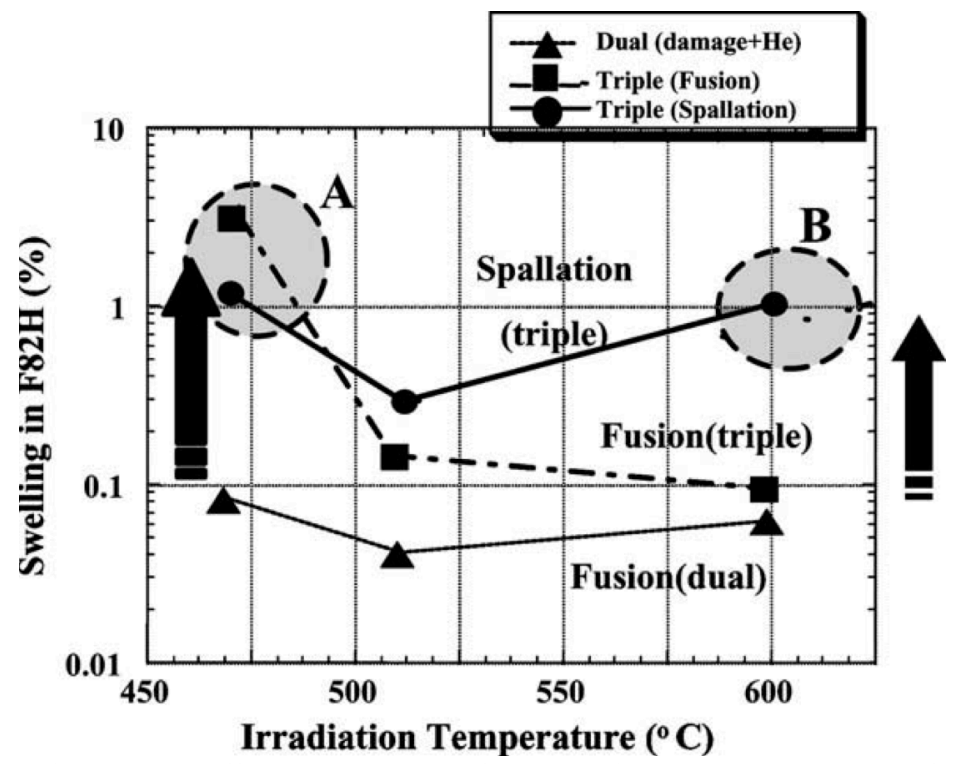

Figure 3 The dependence of swelling of F82H steels on irradiation temperature under these conditions. In the area $A$ the synergistic effect of displacement damage, helium and hydrogen occurred, and in the 

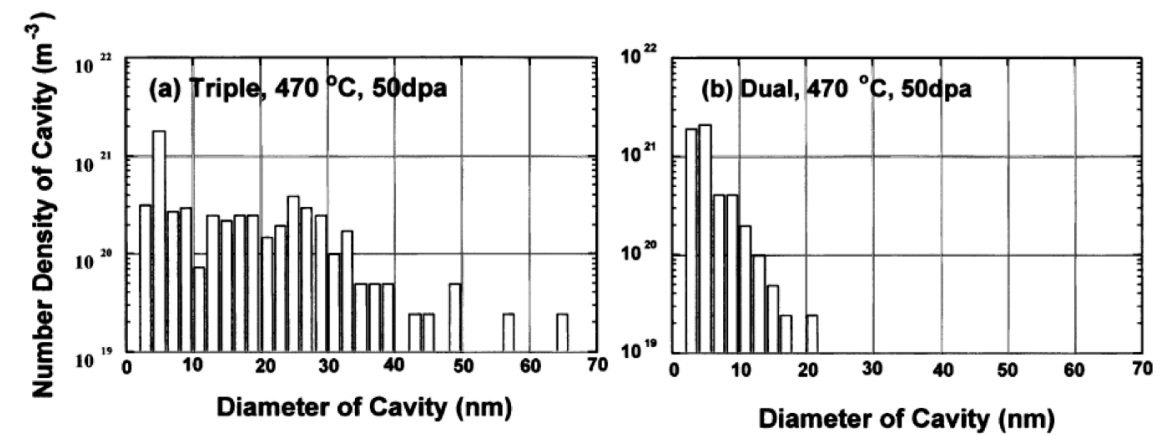

Figure 4 Size distributions of cavities formed in F82H steel irradiated at 470 _C to 50 dpa with the triple and dual ion beams under fusion condition. It was measured at depths from 0.9 to $1.1 \mu \mathrm{m}$. From figure 3 ref. [17].

studied using single $(\mathrm{Fe})$, dual $(\mathrm{Fe}+\mathrm{He})$ and triple $(\mathrm{Fe}+\mathrm{He}+\mathrm{H})$ ion beams. The irradiations by helium and hydrogen atoms were controlled so as to implant over depth ranges from 0.84 to 1.32 microns and 0.88 to 1.39 microns, respectively. The Fe-ions $(10.5 \mathrm{MeV})$ produced displacement damage of $50 \mathrm{dpa}$ at a rate of $1.6 \times 10^{-3} \mathrm{dpa} / \mathrm{s}$. at a depth of $1 \mu \mathrm{m}$, while the $\mathrm{Fe}$-ions produced $150 \mathrm{dpa}$ at a depth of $1.75 \mu \mathrm{m}$ (this was the end-of-range), thus avoiding any effects from the added ions. These two papers demonstrate a large synergistic effect associated with hydrogen implantation simultaneously with displacement damage and helium implantation. This effect yields a 40 -fold increase at $470^{\circ} \mathrm{C}$ in swelling for a triple beam irradiation of $50 \mathrm{dpa}, 18 \mathrm{appm}$ $\mathrm{He} / \mathrm{dpa}$, and $70 \mathrm{appm} \mathrm{H/dpa} \mathrm{(3.2 \%} \mathrm{swelling),} \mathrm{compared} \mathrm{to} \mathrm{a} \mathrm{dual} \mathrm{beam} \mathrm{irradiation} \mathrm{of} 50 \mathrm{dpa}$ and $18 \mathrm{appm} \mathrm{He/dpa} \mathrm{(0.08 \%} \mathrm{swelling).} \mathrm{In} \mathrm{refs.} \mathrm{[17,18]} \mathrm{a} \mathrm{comparison} \mathrm{is} \mathrm{made} \mathrm{for} \mathrm{the} \mathrm{dual} \mathrm{and} \mathrm{triple}$ beam irradiations that includes the number density of cavities, the root mean cubed cavity diameter and the percentage of swelling at three temperatures, 470,510 , and $600^{\circ} \mathrm{C}$. A third set of irradiation conditions are also reported where the $\mathrm{He}$ and $\mathrm{H}$ implantation doses are changed to $180 \mathrm{appm} \mathrm{He/dpa} \mathrm{and} 1700 \mathrm{appm} \mathrm{H/dpa,} \mathrm{respectively} \mathrm{(identified} \mathrm{as} \mathrm{"spallation"} \mathrm{condition),} \mathrm{with}$ all other experimental parameters remaining the same.

For our discussion here we refer the reader to the in [18], (Figure 2 and Figure 3 here). that also include earlier results from ref. [17]. First, we compare the dual beam and triple beam experiments that only differ with respect to the presence of hydrogen implantation and mimic fusion conditions with regards to $\mathrm{He}$ and or $\mathrm{H}$ implant dose. At $470^{\circ} \mathrm{C}$, where the large enhancement in swelling is seen, we note that the number density of cavities for the two types of irradiations are nearly the same and the increased swelling is a result of the large RMC cavity diameter in the triple beam irradiation (11.2 vs $6.7 \mathrm{~nm}$ ) (Table 1 in ref. [17]). In figure 3 of ref. [17] (our Figure 4) the size distribution of cavities for the dual and triple beam experiments are compared suggesting a bimodal distribution in the case of the triple beam experiment and hence bias driven cavity growth for the triple beam irradiation. This figure also suggests a critical cavity diameter for the triple beam experiment of 10-12 nm. Possible explanations for this result is that hydrogen has either reduced the critical cavity size or changed the diffusion bias for vacancy accumulation at bubble embryos. At $510^{\circ} \mathrm{C}$ this synergistic effect of larger cavities appears to be greatly reduced and almost gone by $600^{\circ} \mathrm{C}$.

The third irradiation condition where the helium dose is increased by a factor of 10 and the hydrogen dose is increased by a factor of 24 provides some additional important information about the role of hydrogen. The number density of cavities at $470^{\circ} \mathrm{C}$ is $\sim 10$ times that of the first two experiments and at $510^{\circ} \mathrm{C}$ it is about a factor of three greater. The cavity diameter is about the same as in the triple beam experiment with the lower dose $\mathrm{He}$ and $\mathrm{H}$ implants, about $40 \%$ larger at $470^{\circ} \mathrm{C}$, and $62 \%$ at $510^{\circ} \mathrm{C}$, while at $600^{\circ} \mathrm{C}$ the $\mathrm{RMC}$ diameter more than doubles. If we focus 

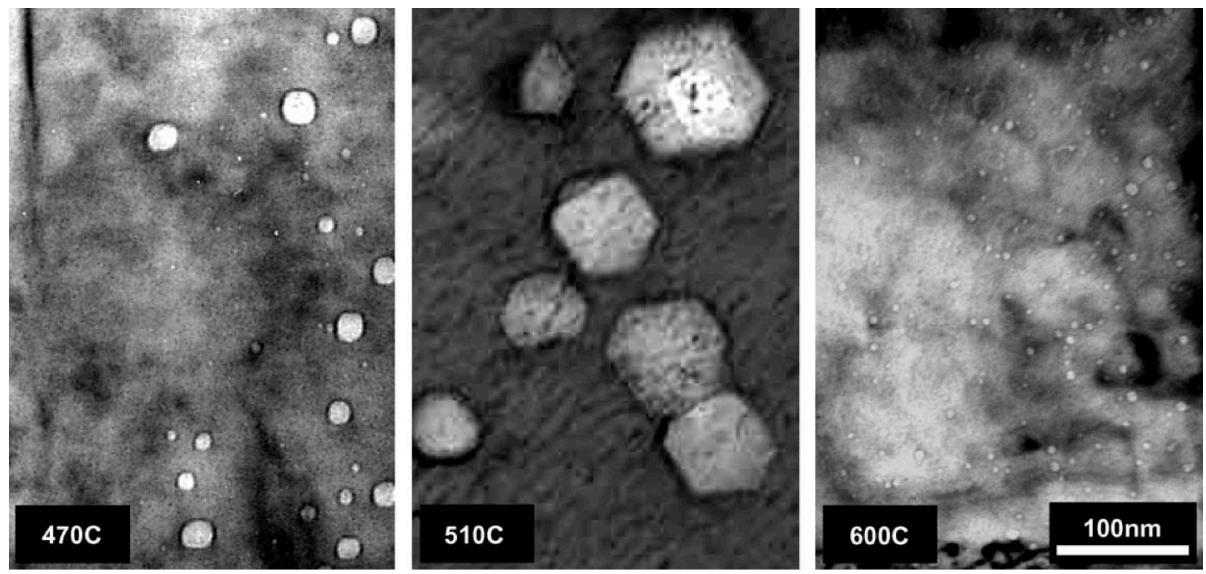

Figure 6: Cavity structures in $\mathrm{Fe}-12 \% \mathrm{Cr}$ alloys irradiated by triple ion beams at different temperatures. A bi-modal cavity distribution was confirmed at low and high temperatures. From ref [19].

on the lower temperature data, it appears that the presence of hydrogen can lead to two effects: it can increase the number of small cavities, and it can accelerate the bias driven cavity growth of helium bubbles. As the temperature increases, the synergistic effects due to hydrogen diminish and possibly disappear, and hence the high temperature $\left(600^{\circ} \mathrm{C}\right)$ large swelling seen in the third irradiation condition with 10 times the $\mathrm{He}$ is due to the high temperature and the high helium concentration alone, as already explained in ref. [18].

In ref. [19] two model F/M alloys were studied, Fe$12 \% \mathrm{Cr}$ and $\mathrm{Fe}-9 \% \mathrm{Cr}$ at 470,510 , and $600^{\circ} \mathrm{C}$. The triple beam irradiation conditions were somewhat different from the earlier work on $\mathrm{F} 82 \mathrm{H}$ in that the $\mathrm{He}$ and $\mathrm{H}$ to dpa ratios (10 and 40 appm/dpa) were significantly lower while the dpa implantation profile and the depth where the $\mathrm{He}$ and $\mathrm{H}$ were implanted were the same as was the dpa dose rate and average dpa (50 dpa) in the $\mathrm{He} / \mathrm{H}$ implant region of the specimens. A maximum was observed in the swelling $\%$ at $510^{\circ} \mathrm{C}$. The cavity number density in the $\mathrm{Fe}-12 \% \mathrm{Cr}$ sample is observed to increase by a factor of $\sim 5$ at $470{ }^{\circ} \mathrm{C}$ while it increases by a factor of $\sim 10$ at $600^{\circ} \mathrm{C}$ relative to its minimum of $\sim 0.2 \times 10^{20} \mathrm{~m}^{-3}$ at $510^{\circ} \mathrm{C}$. An opposite trend is observed for the cavity diameter. At $470^{\circ} \mathrm{C}$ it is $\sim 15 \mathrm{~nm}$, and at $600^{\circ} \mathrm{C}$ it is $\sim 5 \mathrm{~nm}$ compared to a maximum at $510^{\circ} \mathrm{C}$ of $\sim 50$ $\mathrm{nm}$. This maximum in the size again points to one of two possibilities: reduction in the critical $\mathrm{He}$ bubble radius or an increase in the diffusion bias. The $4 \%$ swelling at $510^{\circ} \mathrm{C}$ is $\sim 10$ times greater than at 470 or $600^{\circ} \mathrm{C}$. These results are summarized in Figure 5

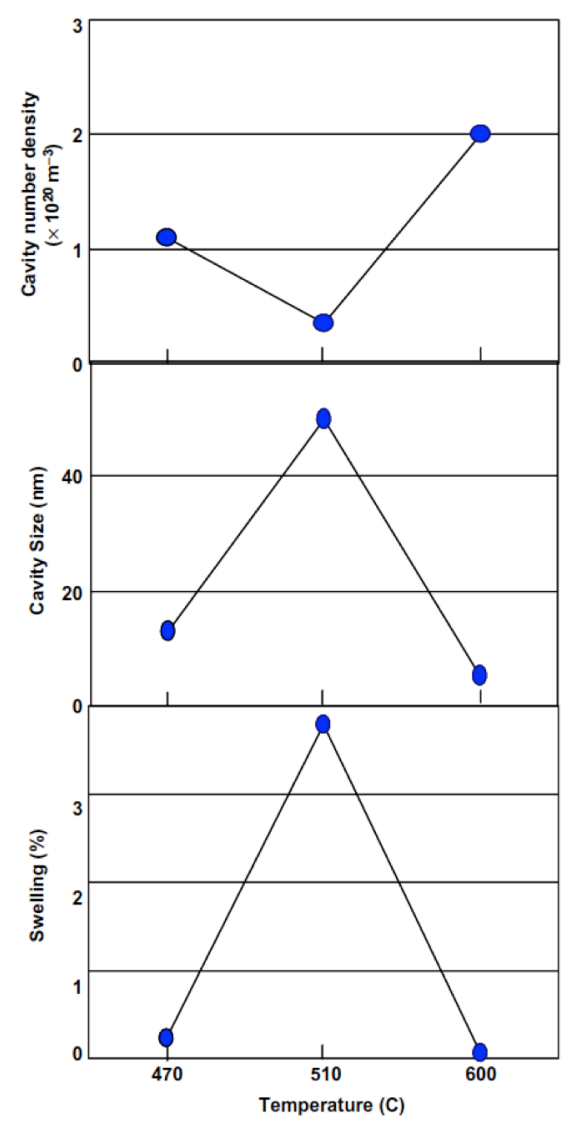

Figure 5 Temperature dependence of cavity number density, size and swelling in $12 \mathrm{Cr}$ alloys irradiated by triple ions. From ref. [19]. 
While the results of the Fe-Cr experiments from the TIARA laboratory are qualitatively similar to their earlier MSIB work on F82H, an important new observation is revealed. At a temperature below the maximum, the swelling cavity size decreases, as it does at a temperature above the maximum. The temperature window of the synergistic swelling effect of the hydrogen in this study is less than $130{ }^{\circ} \mathrm{C}$. In this work dual beam irradiations with $\mathrm{Fe}+\mathrm{H}$ exhibited no formation of bubbles. Hence, it is reasonable to conclude - as in the much earlier paper [12]- that hydrogen is interacting with helium clusters of bubbles. The experimental results suggest that at temperatures below the maximum swelling temperature, hydrogen does not accelerate cavity growth, but may stabilize small $\mathrm{He}-\mathrm{V}$ clusters, while at higher temperatures the hydrogen diffuses too rapidly out of the system and hence cannot interact with the developing He-V clusters. It is interesting that it is reported in [19] that bimodal cavity distributions are seen below and above the temperature of maximum swelling as indicated in Figure 6, but there does not seem to be an explanation for this observation. High-resolution electron microscopy of triple beam irradiated $\mathrm{Fe}-14 \% \mathrm{Cr}$ shown in Figure 7 indicates that even at higher temperatures the faceted cavity structure is still extant although accelerated void growth is not [23].

That hydrogen is a fast diffuser is well understood; it is very interesting that for the F82H study, simulating the spallation environment, where synergistic effects are observed, that no hydrogen could be found in the specimens after irradiation [18]. So, we must, for the moment, conjecture that while hydrogen is able to increase swelling over a narrow temperature range, and is able to stabilize small cavities of helium, these effects with respect to hydrogen appear to be catalytic and hence dependent on the non-equilibrium steady state concentration of hydrogen in the material while under irradiation and at temperature.

There is very little mechanical property data involving radiation damage accumulation from triple MSIBs on F/M steels. There is some data reported by the TIARA group that indicates that the hydrogen has a synergistic effect on mechanical properties under triple beam irradiation conditions when compared with single beam ( $\mathrm{Fe}$ ions to produce dpa) and dual beams $(\mathrm{Fe}+\mathrm{He})$ [21]. In these experiments $\mathrm{F} 82 \mathrm{H}$ steels were used and the specimens were irradiated at the TIARA facility at 270,360 , and $430{ }^{\circ} \mathrm{C}$. Dual irradiation was also performed with simultaneous beams of $10.5 \mathrm{MeV} \mathrm{Fe}$ and $1.05 \mathrm{MeV}$ He ions. Triple irradiation was done with simultaneous beams of $10.5 \mathrm{MeV} \mathrm{Fe}, 1.05 \mathrm{MeV} \mathrm{He}$, and 0.38 $\mathrm{MeV} \mathrm{H}$ ions using energy degraders for helium and hydrogen atoms for both the dual and triple beam cases. Helium and hydrogen were implanted in the depth range of about $0.8-1.3 \mathrm{um}$ from the specimen surface. The irradiation was performed to 20-50 dpa at the depth of 1.0 um from the irradiation surface. The damage rate was about $1.0 \times 10^{3} \mathrm{dpa} / \mathrm{s}$ compared to $1.6 \times 10^{-3} \mathrm{dpa} / \mathrm{s}$ in the earlier papers of this group. The ratios of helium and hydrogen to dpa were about $10 \mathrm{appm}$ $\mathrm{He} / \mathrm{dpa}$ and $40 \mathrm{appm} \mathrm{H} / \mathrm{dpa}$, respectively. These beam conditions, except for the dpa dose rate, are similar to those used in earlier experiments.

Figure 8 summarizes the results obtained which compare micro-hardness measurements for the triple beam irradiations to dual and single beam irradiations at $20 \mathrm{dpa}$ and at two temperature: 270

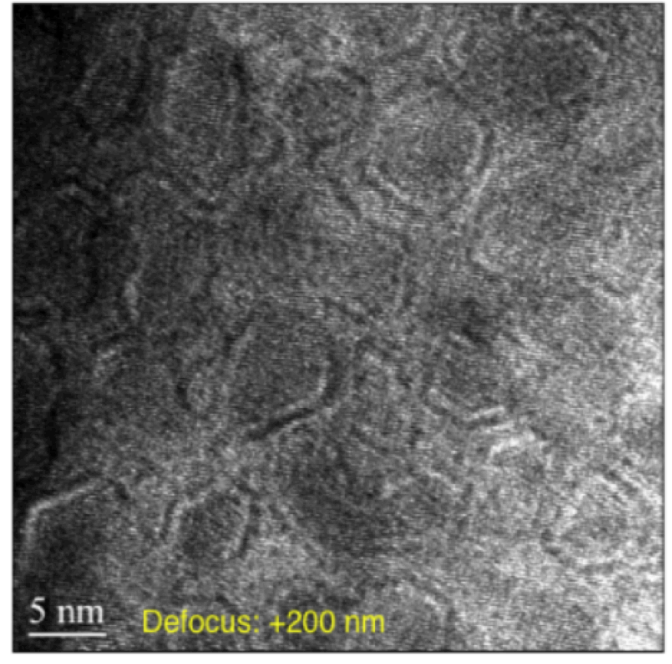

Figure 7: New void like structure is seen in $625^{\circ} \mathrm{C}$ triple beam irradiation of $\mathrm{Fe}-14 \% \mathrm{Cr}$, 40dpa, 40 appm H/dpa, and 15 appm He/dpa. Note the similar faceting of the cavities shown to those in Figure 6, both of which are the product of a synergistic hydrogen effect. From ref [23] 
and $360{ }^{\circ} \mathrm{C}$. What is observed is that the presence of $\mathrm{He}$ or $\mathrm{He}+\mathrm{H}$ in the $270{ }^{\circ} \mathrm{C}$ irradiations has no measureable effect on the micro hardness. But a systematic increase in the micro-hardness is observed at $360{ }^{\circ} \mathrm{C}$ for the dual and then the triple beam irradiations compared to the single beam irradiation. The authors note that at $270{ }^{\circ} \mathrm{C}$ for the dual beam irradiation there are no cavities (He bubbles) observable. Hence one might deduce that, as previously suggested, the hydrogen only seems to have a synergistic effect when He clusters are available with which the $\mathrm{H}$ can interact.

We remark in passing that the authors report a peak in the swelling curve at $430{ }^{\circ} \mathrm{C}$ for the dual beam irradiation [21]. As we noted earlier, the width of the swelling curve for the triple beam irradiation study of $\mathrm{Fe}-12 \% \mathrm{Cr}$ was $\sim 130{ }^{\circ} \mathrm{C}$. This suggests that the peak in the swelling curve for the triple beam irradiation of $\mathrm{F} 82 \mathrm{H}$ might be at about the same temperature and that the dramatic swelling seen for $\mathrm{F} 82 \mathrm{H}$ at $470^{\circ} \mathrm{C}$ could be significantly greater than $3.2 \%$, maybe as much as $32 \%$.

\subsubsection{Formation of complex chemical species}

Based on earlier experimental work, we have shown that the observed synergistic effect of enhanced swelling due to $\mathrm{H}$ requires the presence of He or more likely He-clusters and/or bubbles. This brings us to the question of how hydrogen, a strong reducing agent, would interact with other elements in an F/M steel. We have recently conducted an experiment with triple ion-beam irradiation on an ODS alloy (K3). We have observed evidence for a complex synergistic effect associated with $\mathrm{H}$ and simultaneous displacement damage. Details about the experimental conditions and main results are as follows. The chemical composition (in wt.\%) of the ODS steels was: C: 0.08 , Si: 0.033 , Cr: 16 , W: $1.82, \mathrm{Al}: 4.59$, Ti: $0.28, \mathrm{Y}_{2} \mathrm{O}_{3}: 0.368$, and Fe: balance. The ODS steel samples subjected to $(\mathrm{Fe}+\mathrm{He})$ dual-ion-beam irradiation and $(\mathrm{Fe}+\mathrm{He}+\mathrm{H})$ triple-ionbeam irradiation using $24.2 \mathrm{MeV} \mathrm{Fe}{ }^{8+}$ ions for displacement damage, $1.7 \mathrm{MeV} \mathrm{He}+$ ions for helium injection, and $525 \mathrm{KeV} \mathrm{H}^{+}$ions for hydrogen injection were conducted at the JANNUS facility in Saclay, France. The irradiation temperature was $600 \pm 5^{\circ} \mathrm{C}$. The implantation depth of transmutation gases was over a region extending from 1.8 to 2.6 microns beneath the specimen surface to avoid overlapping with the implanted Fe-ion region that was over a depth range extending from 2.8 to 3.6 microns beneath the specimen surface. The displacement damage at the peak position of the Fe implantation was $60 \mathrm{dpa}$ and the specimens were irradiated at a dose rate of $\sim 10^{-3} \mathrm{dpa} / \mathrm{s}$. The nominal conditions for ion irradiation at helium and hydrogen implantation regions are as follows: the displacement damage gradually increases from $16 \mathrm{dpa}$ (at $1.8 \mu \mathrm{m})$ to $30 \mathrm{dpa}($ at $2.6 \mu \mathrm{m})$ the helium to dpa ratio was $\sim 15 \mathrm{appm} / \mathrm{dpa}$ and the hydrogen to dpa ratio was $40 \mathrm{appm} / \mathrm{dpa}$ with a variation of $\sim 10 \%$ over the $\mathrm{H}$ and $\mathrm{He}$ implant depth. These beam conditions are similar to those reported for studies on $\mathrm{F} 82 \mathrm{H}$ and $\mathrm{Fe} 9-12 \% \mathrm{Cr}$ from the TIARA group.

A high density of mono-modal size cavities, $\sim 4 \mathrm{~nm}$ diameter, are seen using high-resolution electron microscopy (Figure 9). The cavities tend to be associated with He bubble formation at ODS nano-particles of dimensions $<2 \mathrm{~nm}$ distributed in the $\mathrm{K} 3$ specimen.

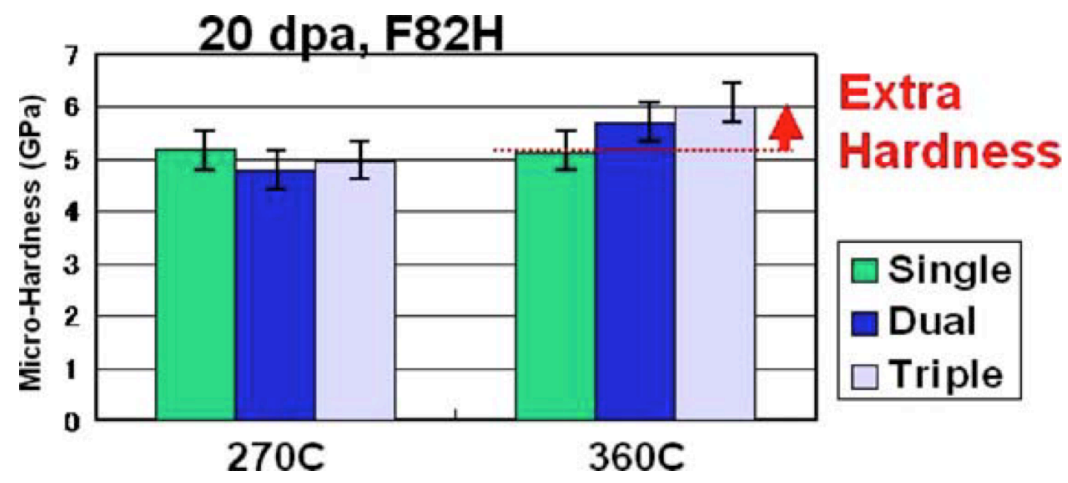

Figure 8: Changes of hardness of F82H steel irradiated to $20 \mathrm{dpa}$ at 270 and $360{ }^{\circ} \mathrm{C}$ for three beam conditions, single, dual and triple. From ref [21]. 


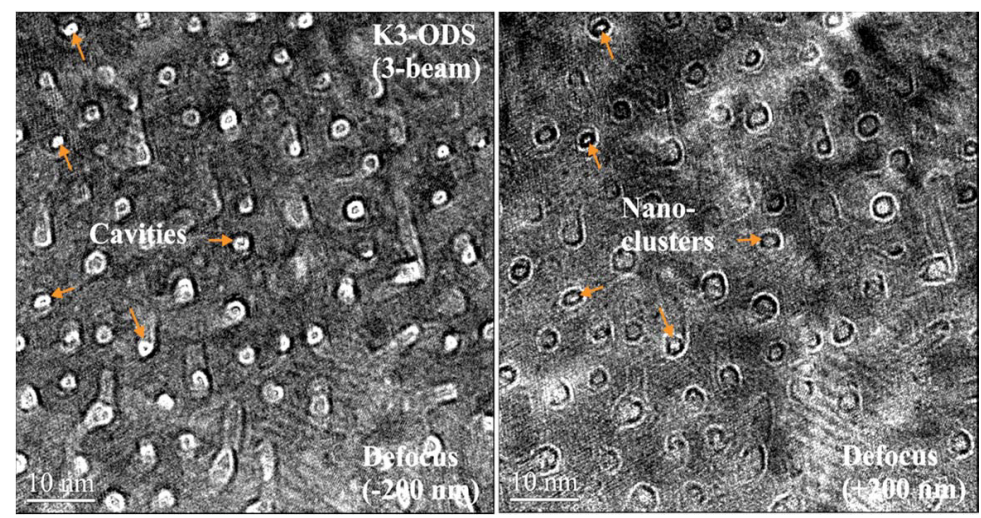

Figure 9: Bright-field TEM images, (left) under-focus $(-200 \mathrm{~nm})$ and (b) over-focus (+200 nm), show the formation of high-density cavities in association with nanoclusters $(\mathrm{d}<2 \mathrm{~nm})$ that are more readily seen in (right) under an over-focus condition.

The adverse effect of hydrogen implantation on enhancing bubble-to-void conversion is evidenced in Figure 10, in which facetted voids with diameters from 7 to $20 \mathrm{~nm}$ were observed in local regions. A diffraction and chemical study was made to determine what the structure (and deduced molecular species) was in these cavity regions. The result was the identification of a nanoscale hydroxide phase, based on the $\mathrm{HFe}_{5} \mathrm{O}_{8}$ compound, co-located at the cavity sites, The methodology to make this determination was to use selected-area fast Fourier transform (FFT), diffraction pattern simulation, and energy dispersive x-ray (EDX) methods.

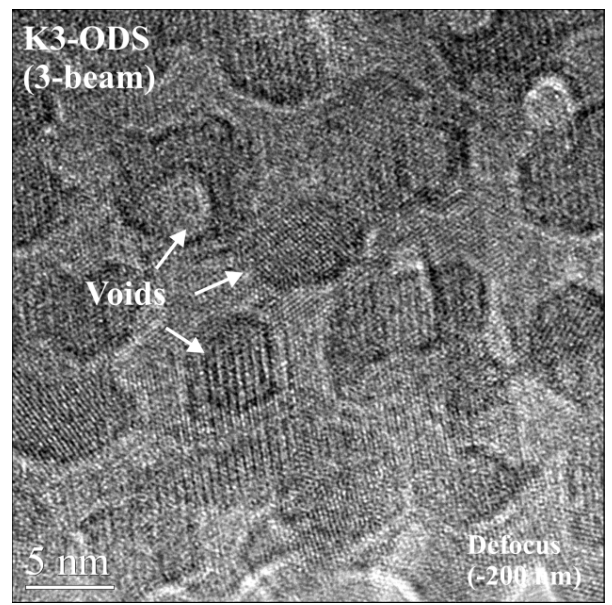

Figure 10: Large and facetted voids, presumably caused by the presence of hydrogen during the triple beam irradiation, were observed at very local regions of the K3 sample. Images were taken under a defocus of $200 \mathrm{~nm}$

The results are displayed in Figure 11, 12, and 13. $\mathrm{HFe}_{5} \mathrm{O}_{8}$ has a hexagonal structure (space group: P63mc) with lattice parameters: $\mathrm{a}=0.598 \mathrm{~nm}$ and $\mathrm{c}=0.937 \mathrm{~nm}$ [17]. Figures 7 and 8 show the identification of the $\mathrm{HFe}_{5} \mathrm{O}_{8}$ phase that were oriented in two major zone axes, [0001] and $[10 \overline{1} 1]$, respectively, through the comparison of the FFT images with the simulated diffraction patterns. Image processing of observed high-resolution images using auto correlation function (ACF) was also employed to better reveal the periodicity of nanoscale ordering. A sixfold symmetry of the $\mathrm{HFe}_{5} \mathrm{O}_{8}$ nanostructure can be clearly seen in Figure 11 oriented in the [0001]-zone. Although hydrogen cannot be detected by using EDX method, the result shown in Figure 13 indicate that the ratio of $\mathrm{O}$ to $(\mathrm{Fe}+\mathrm{Cr}+\mathrm{Al})$ in at. \% is 1.68 that is consistent with $\mathrm{O} / \mathrm{Fe}$ (=1.6) in $\mathrm{HFe}_{5} \mathrm{O}_{8}$. This suggests the formation of a $\mathrm{HFe}_{5} \mathrm{O}_{8}$ phase with $\mathrm{Cr}$ and $\mathrm{Al}$ as substitutional solute atoms, i.e., $\mathrm{H}(\mathrm{Fe}, \mathrm{Cr}, \mathrm{Al})_{5} \mathrm{O}_{8}$. The presence of trace amounts $(0.17$ at.\%) of yttrium 
detected from the hydroxide phase suggests the decomposition and dissolution of oxide nanoparticles/clusters previously located in the region as a result of the formation of hydroxide compound caused by the synergistic effect of displacement damage (ballistic effect) and the availability of a steady state concentration of hydrogen via implantation.

A possible clue as to the details of the mechanism leading to the production of $\mathrm{HFe}_{5} \mathrm{O}_{8}$ can be found in earlier investigations of the stability of oxide particles under irradiation conditions from neutrons, electrons, and heavy-ions $[24,25,26]$. What is revealed in these articles is that the oxide particles can either disappear (smaller particles) or can be reduced in size (larger particles. In [26] it is argued that a combination of ballistic decomposition and diffusion are both operating to lead to this oxide particle evolution. In the case of ion-beam experiments performed at elevated temperatures, there is no time for back diffusion of ballistic debris and the consequence is the development of a "halo" of smaller oxide particles around the parent particle. This suggests that there can be a steady state population of mobile elemental components of the parent oxide particles, all of which can be chemically reduced by the steady state non-equilibrium population of implanted hydrogen. This halo should not be confused with the well known core-shell structure that is seen for these ODS particles as a result of their non-equilibrium nature due to incomplete heat treatment. An example of this halo effect (Figure 14) was seen in the same specimen that yielded evidence for the production of $\mathrm{HFe}_{5} \mathrm{O}_{8}$. 


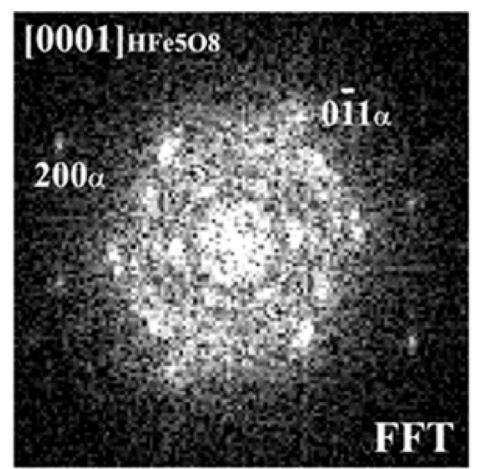

Simulated [0001] HFе5о8 pattern
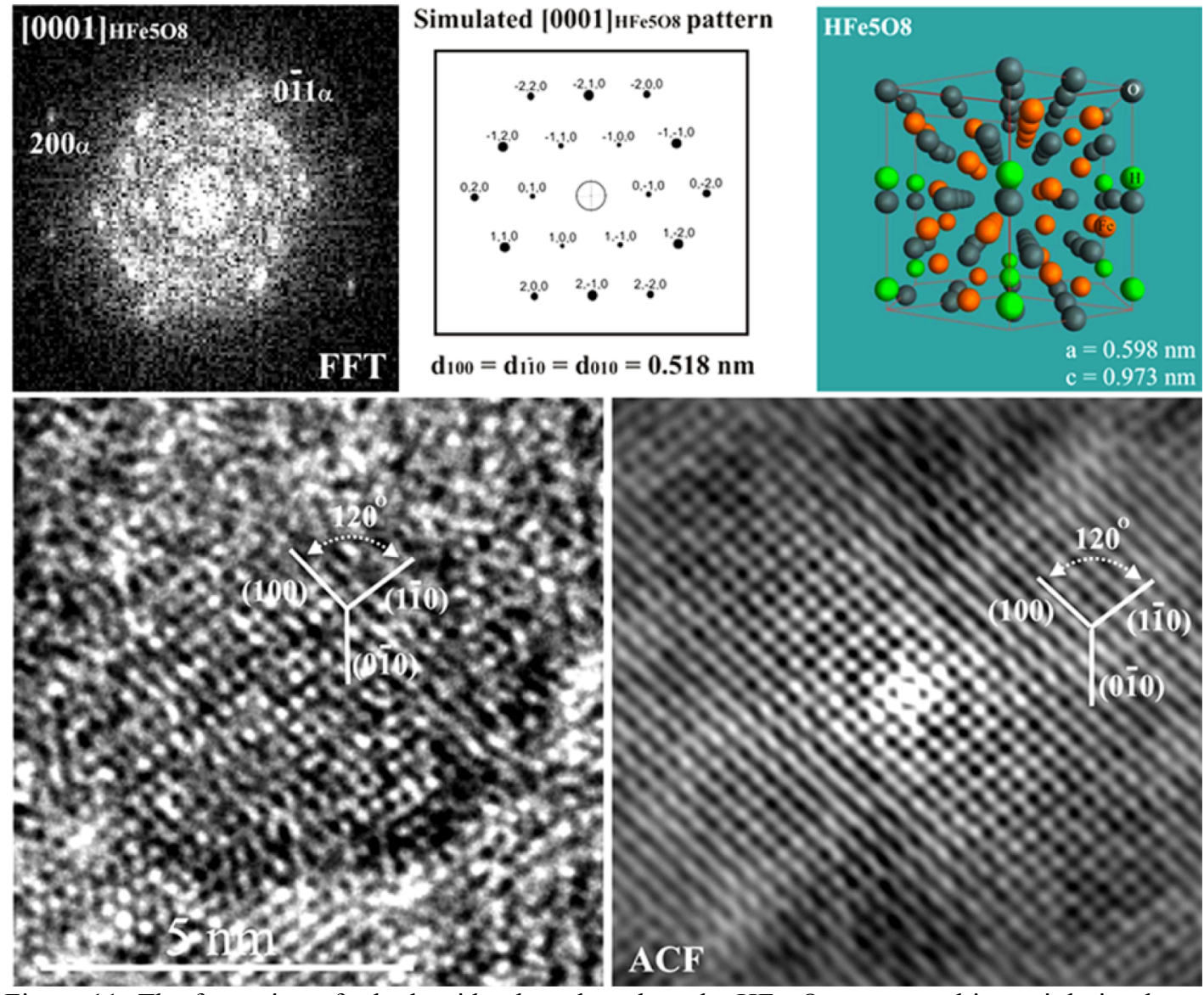

Figure 11 The formation of a hydroxide phase based on the $\mathrm{HFe} 5 \mathrm{O} 8$ compound in a triple-ion-beam irradiated K3 sample. The existence of the hydroxide compound was identified though FFT image of the [0001]-zone, simulated [0001] diffraction pattern, and image processing using auto correlation function $(\mathrm{ACF})$ that exaggerates the periodicity of ordering shown in observed high-resolution image in the $[10 \overline{1} 1]$-zone. 


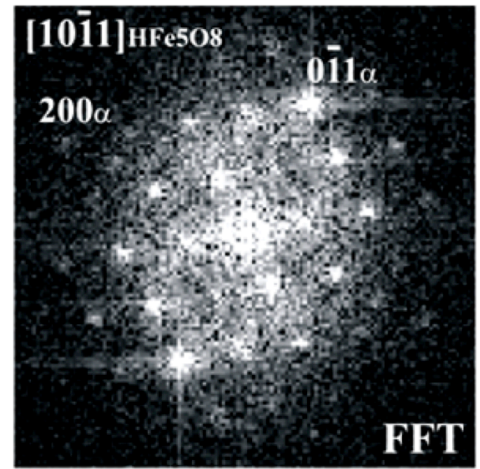

Simulated $[10 \overline{1} 1]_{\text {HFes08 pattern }}$

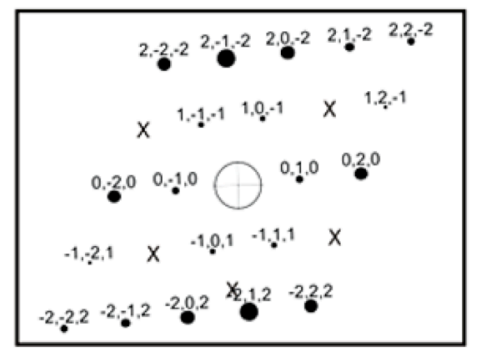

$\operatorname{din}_{101}=\operatorname{di}_{11}=0.453 \mathrm{~nm}$

$d_{010}=0.518 \mathrm{~nm}$
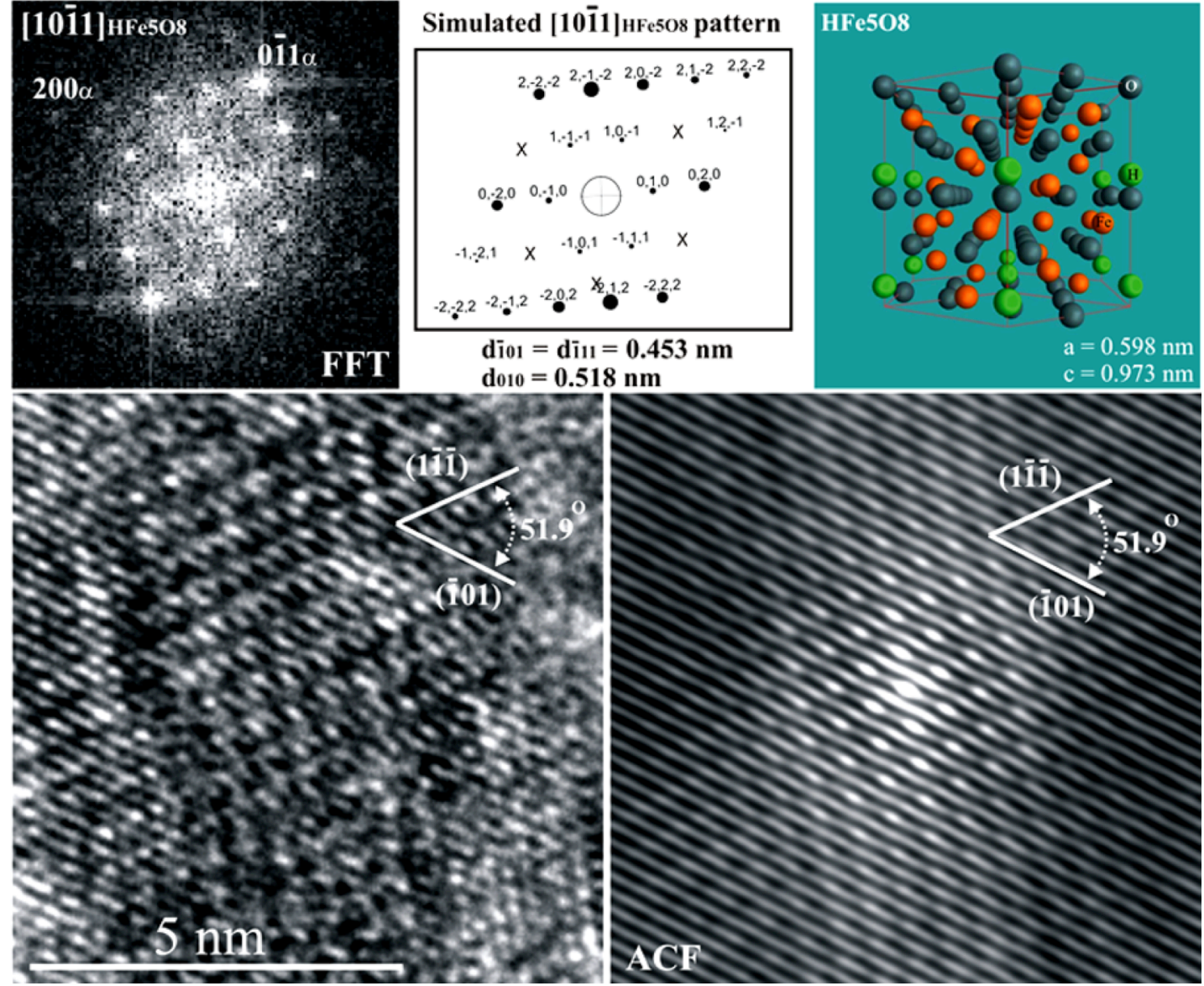

Figure 12 The formation of a hydroxide phase based on the $\mathrm{HFe} 5 \mathrm{O} 8$ compound in triple-ion-beam irradiated sample. The existence of the hydroxide compound was identified though FFT image of the

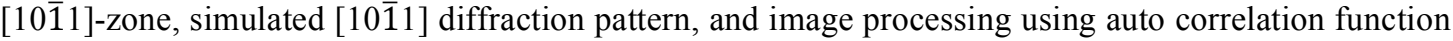
(ACF) that exaggerates the periodicity of ordering shown in observed high-resolution image in the

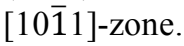




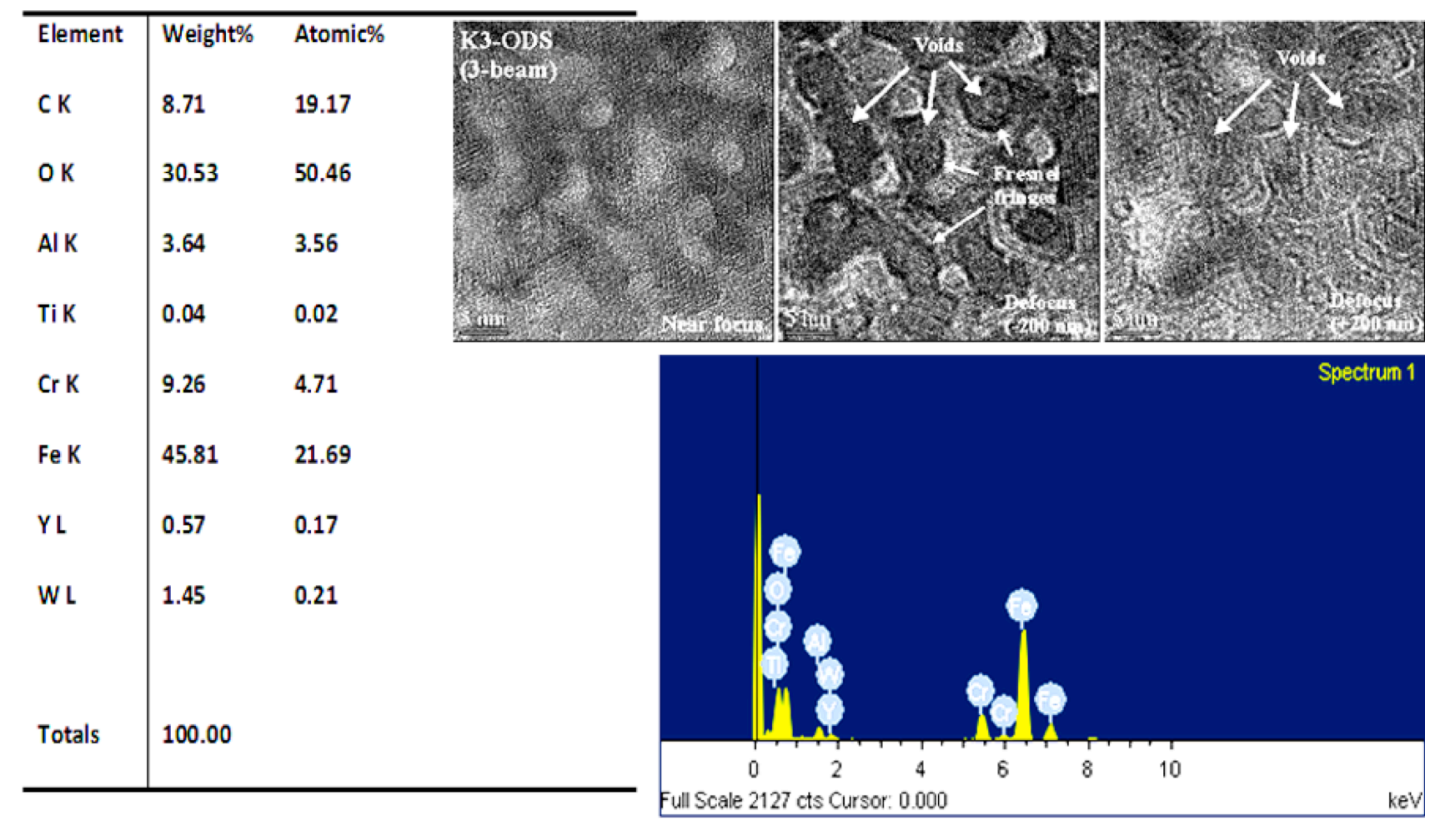

Figure 13 The result of energy-dispersive $\mathrm{x}$-ray (EDX) shows that the ratio of $\mathrm{O}$ to $(\mathrm{Fe}+\mathrm{Cr}+\mathrm{Al})$ in atomic $\%$ is 1.68 , which is close to $\mathrm{O} / \mathrm{Fe}(=1.6)$ in $\mathrm{HFe}_{5} \mathrm{O}_{8}$, suggests the existence of $\mathrm{H}(\mathrm{Fe}, \mathrm{Cr}, \mathrm{Al}) 5 \mathrm{O} 8$.
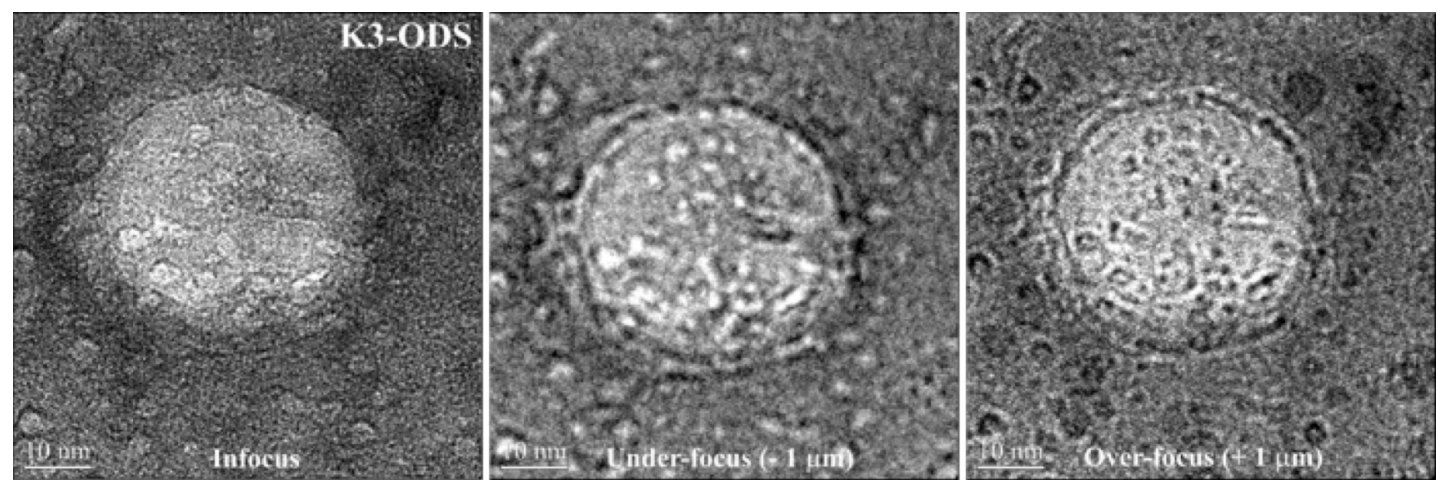

Figure 14 Observation of ballistic assisted decomposition of a large ODS particle in the K3 material in which the $\mathrm{HFe}_{5} \mathrm{O}_{8}$, compound was observed. 


\section{Modeling triple $\mathrm{Fe} / \mathrm{He} / \mathrm{H}$ implantation:}

In light of all the evidence for hydrogen-helium synergisms, but also considering the many uncertainties and knowledge gaps discussed in the previous sections, devising a computational model to study synergistic effects is no trivial task. First of all, such a model must capture the incipient stages of $\mathrm{He}-\mathrm{V}, \mathrm{H}-\mathrm{V}$, and $\mathrm{He}-\mathrm{H}-\mathrm{V}$ cluster formation, where the seeds for the subsequent swelling behavior at the macroscopic scale are likely planted. This requires the formulation of a triple-interaction model for which there is presently very little experimental insight. Second, the model must be capable of reaching doses sufficiently high to display a synergistic effect. Both of these are daunting tasks that require significant computational effort. Below we discuss the available computational data and propose a model that is informed by such results and furthermore extends them to relevant doses in terms of the swelling achieved. Considering the complex behaviors attendant to bubble formation and synergistic interactions, the model is still insufficient to explain some of the outstanding questions posed in earlier sections. However, it can identify areas where experimental efforts can be more effectively focused to increase our understanding, as well as serve as the baseline for future calculations and theoretical improvements. In what follows, we discuss the main building blocks of the model, starting with understanding gained at the nanometric scale form previous simulation results.

\subsection{Computational evidence of vacancy/He/H interactions in Fe}

Most of the microscopic experimental evidence regarding interactions of $\mathrm{He}$ and $\mathrm{H}$ with point defects suggests that $\mathrm{He}$ atoms are more effective for void formation than $\mathrm{H}$ atoms [27, 28]. However, experiments have not provided a clear indication beyond several qualitative arguments of the effect of He accumulation on $\mathrm{H}$ and vice versa. The presence of $\mathrm{He}$ within the crystal has been proved experimentally to significantly enhance the trapping of hydrogen, even for periods of years after irradiation $[13,29,30]$.

For its part, the computational characterization of $\mathrm{V} / \mathrm{He} / \mathrm{H}$ interaction effects has not fared much better beyond a few calculations of local mechanisms and processes. The computational data comes from three main sources:

Kirsanov et al. [31] have noted that the small binding energy of $\mathrm{H}$ and its high mobility in bulk Fe allows it to find otherwise mobile $\mathrm{He}-2 \mathrm{~V}$ clusters and attach itself to the free vacancy. He-2V clusters are the main carriers of $\mathrm{He}$ during gas void formation, and thus one may expect a delay of helium bubble formation caused by hydrogen's role in sequestering $\mathrm{He}$ in small bubbles, and an increased number of nucleation sites.

(ii) Using DFT calculations, Hayward and Deo [32] analyzed the energetics and structure of small V-He-H bubbles, and explained the observed $\mathrm{He} / \mathrm{H}$ synergy as a consequence of bubble growth through helium induced loop punching, aided by the presence of $\mathrm{H}$ that benefits from an increased area of free surface on which to bind instead of as a direct interaction between $\mathrm{H}$ and He. However, we discount this possibility, as it would require insertion doses much in excess of those present in fusion environments.

(iii) Ortiz et al. [33] also performed DFT calculations of V-He-H complexes and obtained a weak interaction between $\mathrm{H}$ and $\mathrm{He}$ in bubbles. This is in contrast to previous DFT results of a strong trapping of $\mathrm{H}$ at $\mathrm{He}$. The strong preference of $\mathrm{He}$ and $\mathrm{H}$ to occupy regions with low electronic density (such as vacancies) explains this discrepancy, with $\mathrm{V}-\mathrm{He}$ and $\mathrm{V}-\mathrm{H}$ binding forces screening the repulsive interaction between $\mathrm{He}$ and $\mathrm{H}$.

As one can see, the evidence from experimental and computational sources is not necessarily complementary, as in the former case triple ion exposure is seen to result in a reduced population 
of bubbles (although with larger sizes) while in the latter case $\mathrm{H}$ induces a higher number of nucleation points for triple clusters by trapping small, mobile V-He clusters,

\subsection{Model of bubble formation in $\mathrm{Fe}$ in the presence $\mathrm{H}$ and He atoms}

We implement the following model of $\mathrm{V} / \mathrm{He} / \mathrm{H}$ interaction with the following guidelines based on experiment and current theoretical understanding:

- Both $\mathrm{He}$ and $\mathrm{H}$ atoms display extremely fast three-dimensional diffusion.

- Small vacancy clusters can attract $\mathrm{H}$ atoms. However, these atoms do not occupy substitutional vacant sites. Instead they bind (with binding energy: $0.5 \mathrm{eV}$ ) at external tetra or octahedral interstitial positions. Thus, they do not intrinsically stabilize small vacancy clusters.

- He atoms can stabilize small vacancy clusters by occupying vacant sites. However, these $\mathrm{V}$-He complexes can retain some mobility particularly if the number of $\mathrm{He}$ atoms is not equal to the number of vacancies.

- If one $\mathrm{H}$ atom finds one of these mobile $\mathrm{V}-\mathrm{He}$ complexes, turning it into a $\mathrm{V}-\mathrm{He}-\mathrm{H}$ complex, their mobility is then suppressed.

- It is assumed that triple $\mathrm{V}-\mathrm{He}-\mathrm{H}$ clusters are stable across the entire temperature range, such that no vacancies, helium or hydrogen can detrap from these clusters.

The implicit temperature dependence of the above model stems from the competition between two main mechanisms. At lower temperatures, $\mathrm{H}$ and $\mathrm{He}$ atoms are more strongly bound to $\mathrm{V}-\mathrm{H}$ and $\mathrm{V}-\mathrm{He}$ clusters respectively (more potential nucleation points), but the mobility of these clusters is small and there is less coalescence as well as losses to sinks. At high temperatures, nucleated bubbles can coalescence giving rise to larger bubbles, but losses to sinks increase. The optimum compromise for a given set of irradiation conditions as a function of temperature is found at the so-called peak swelling temperature.

The effect of varying the $\mathrm{He} / \mathrm{H}$ ratio may also depend on the temperature. Increasing the amount of $\mathrm{He}$ results in a larger number density of $\mathrm{V}-\mathrm{He}$ clusters. There is not now sufficient $\mathrm{H}$ to populate this enhanced population of $\mathrm{V}-\mathrm{He}$ clusters. This leaves a remnant population of $\mathrm{V}-\mathrm{He}-$ only clusters that can move and coalesce or migrate to sinks. The temperature balance of these two processes may result in higher or lower swelling, depending on the case, Below, we study one temperature at which increasing the $\mathrm{He} / \mathrm{H}$ ratio leads to a reduced swelling.

\subsection{Stochastic cluster dynamics method for long-term damage accumulation}

Here we use the stochastic cluster dynamics method (SCD) [34] to perform all simulations. SCD is a stochastic variant of the mean-field rate theory technique, being an alternative to the standard ordinary differential equation (ODE)-based implementations, that eliminate the need to solve exceedingly large sets of ODEs and which relies instead on sparse stochastic sampling from the underlying kinetic master equation. Rather than dealing with continuously varying defect concentrations in an infinite volume, SCD evolves an integer-valued defect population $N i$ in a finite material volume $\Omega$, thus avoiding combinatorial explosion in the number of ODEs. This makes SCD ideal to treat problems where the dimensionality of the cluster size space is high, e.g., when multispecies simulations involving energetic particles such as $\mathrm{He}, \mathrm{H}$, etc., are of interest simultaneously. SCD recasts the standard ODE system into stochastic equations of the form:

$$
\frac{d N_{i}}{d t}=\widetilde{g}_{l}-\sum_{j} \tilde{s}_{i j} N_{i}+\sum_{j} \tilde{s}_{j i} N_{j}-\sum_{i, j} \tilde{k}_{i j} N_{i} N_{j}+\sum_{j, k} \tilde{k}_{j k} N_{j} N_{k}
$$


where the set $\{\tilde{g}, \tilde{s}, \tilde{k}\}$ represents the reaction rates of $0^{\text {th }}$ (inser tion), $1^{\text {st }}$ (thermal dissociation, annihilation at sinks), and $2^{\text {nd }}$ (binary reactions) order kinetic processes taking place inside $\Omega$.

For the SCD calculations, the baseline parameterization is that used by Marian and Bulatov [34], on top of which the $\mathrm{V} / \mathrm{He} / \mathrm{H}$ model described in Section 5.2 is added in terms of additional energetics and specification of extra key reactions. By way of example, we show in Figure 15 the PKA cumulative damage function $C(E)$ that defines the insertion term.

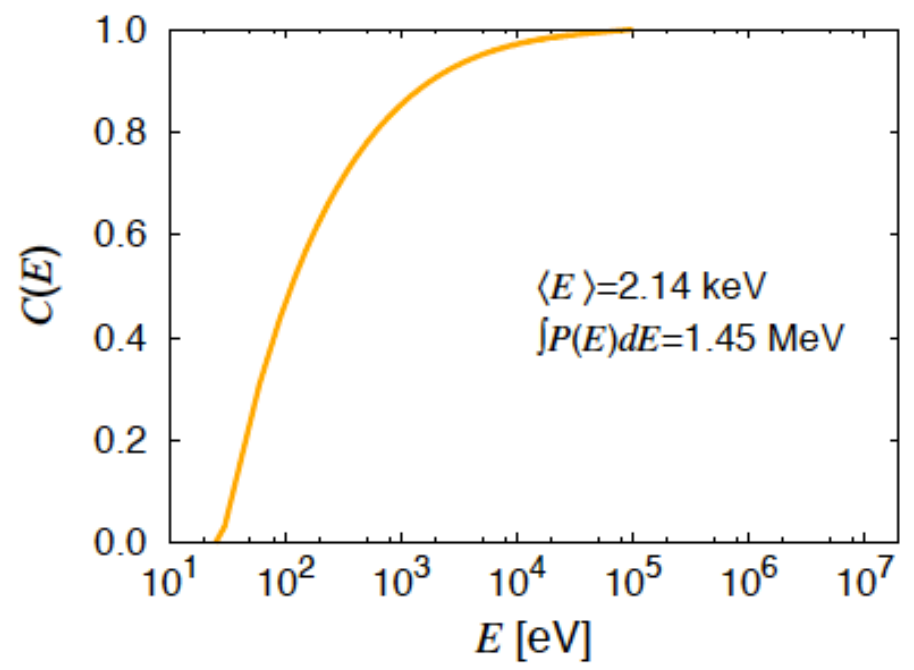

Figure 15: Cumulative damage function for $10.5-\mathrm{MeV}$ Fe ions in Fe from SRIM calculations. The average PKA energy from this function is $\langle E\rangle 2.14 \mathrm{keV}$, while the total damage energy is $1.45 \mathrm{MeV}$.

$C(E)$ is sampled during every insertion event and defect distributions are generated from existing cascade statistics for every PKA energy $E$. This process is repeated until the total damage energy of $1.45 \mathrm{MeV}$ is reached. This process completes a full insertion event, which occurs at a rate consistent with the prescribed dose rate.

\section{Calculations}

The calculations are run up to a total dose of $1 \mathrm{dpa}$ and all defect populations are tallied as a function of dose. Figure 16 shows the evolution of the defect species with dose at a temperature of $510^{\circ} \mathrm{C}$. The calculations reveal interesting information, such as the incubation times of each species' subpopulation, or the metastability of certain types of clusters. 


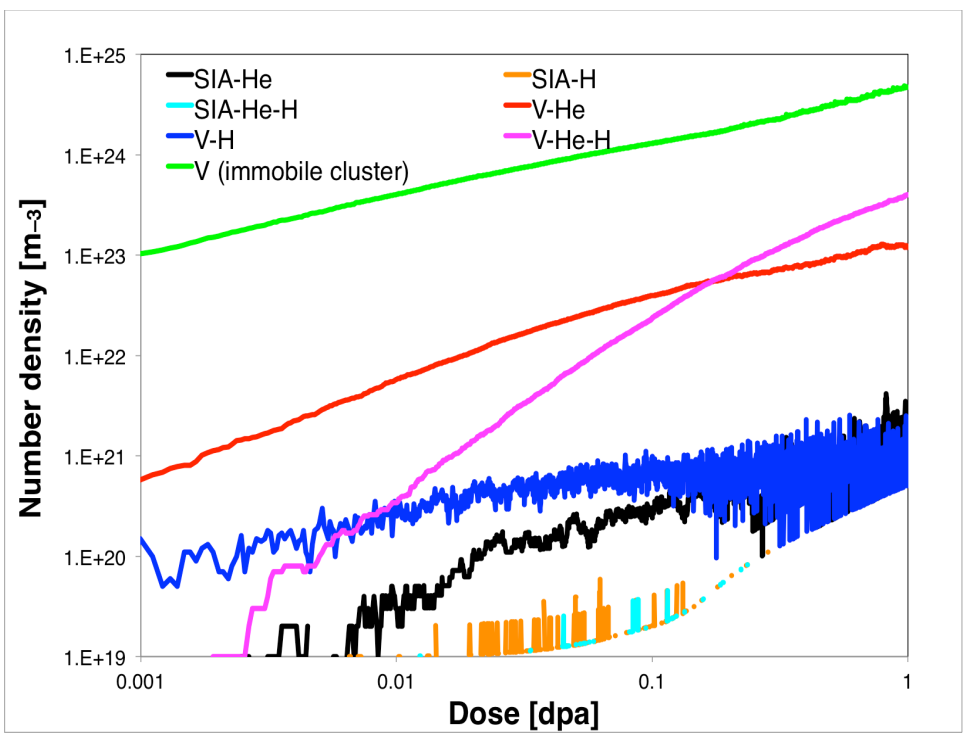

Figure 16: Evolution with dose of all defect species at a temperature of $783 \mathrm{~K}$.

The total amount of swelling $(S)$ can be calculated by summing over the number of vacancies contained in all stable, immobile vacancy clusters, and dividing by the number of lattice sites in the simulation volume:

$$
S=\frac{\Omega_{a} \sum_{i}^{N_{V}} n_{i}}{\Omega \rho_{a}}
$$

where $\Omega_{a}$ is the atomic volume $\rho_{a}$, is the atomic density, and $n_{i}$ is the number of vacancies in cluster $i$. This swelling ratio is plotted in Figure 17 as a function of dose at the four temperatures considered in this study. As the figure shows, the differences are not remarkable, although a temperature dependence can clearly be distinguished. This is what is shown in the inset, where a peak swelling temperature of around $800 \mathrm{~K}$ can be appreciated for the swelling levels after $1 \mathrm{dpa}$. 


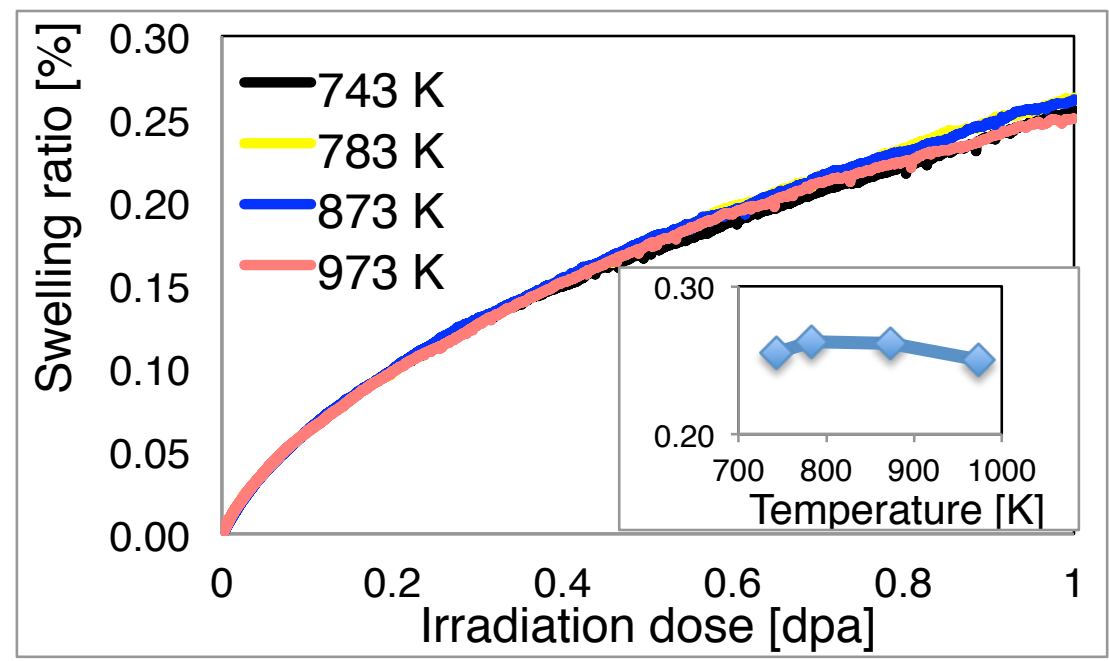

Figure 17: Evolution with dose of the swelling ratio as a function of temperature. The inset shows the amount of swelling after 1 dpa of irradiation.

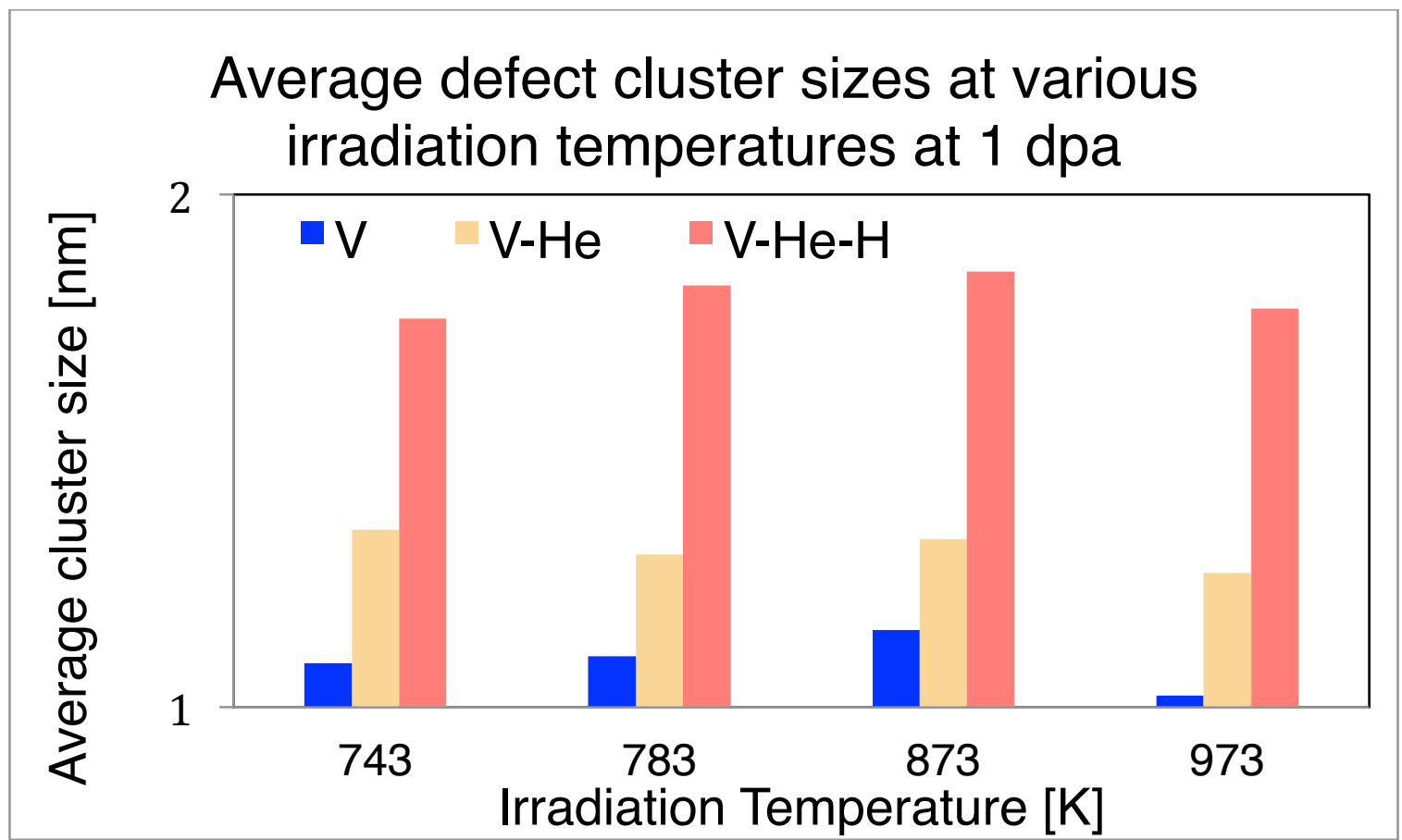

Figure 18: Average vacancy cluster size as a function of temperature after an accumulated dose of $1 \mathrm{dpa}$.

More striking perhaps is the average bubble size after 1 dpa, shown in Figure 18. There, it can be clearly seen that triple $\mathrm{V}-\mathrm{He}-\mathrm{H}$ clusters are significantly larger than their $\mathrm{V}-\mathrm{He}$ and pure $\mathrm{V}$ counterparts. We note that at this dose level, the average size is still too small to be indicative of anything but bubble growth. In other words, $1 \mathrm{dpa}$ is still well below the required dose to achieve runaway void growth and the bubbles are clearly still in their growth phase. 


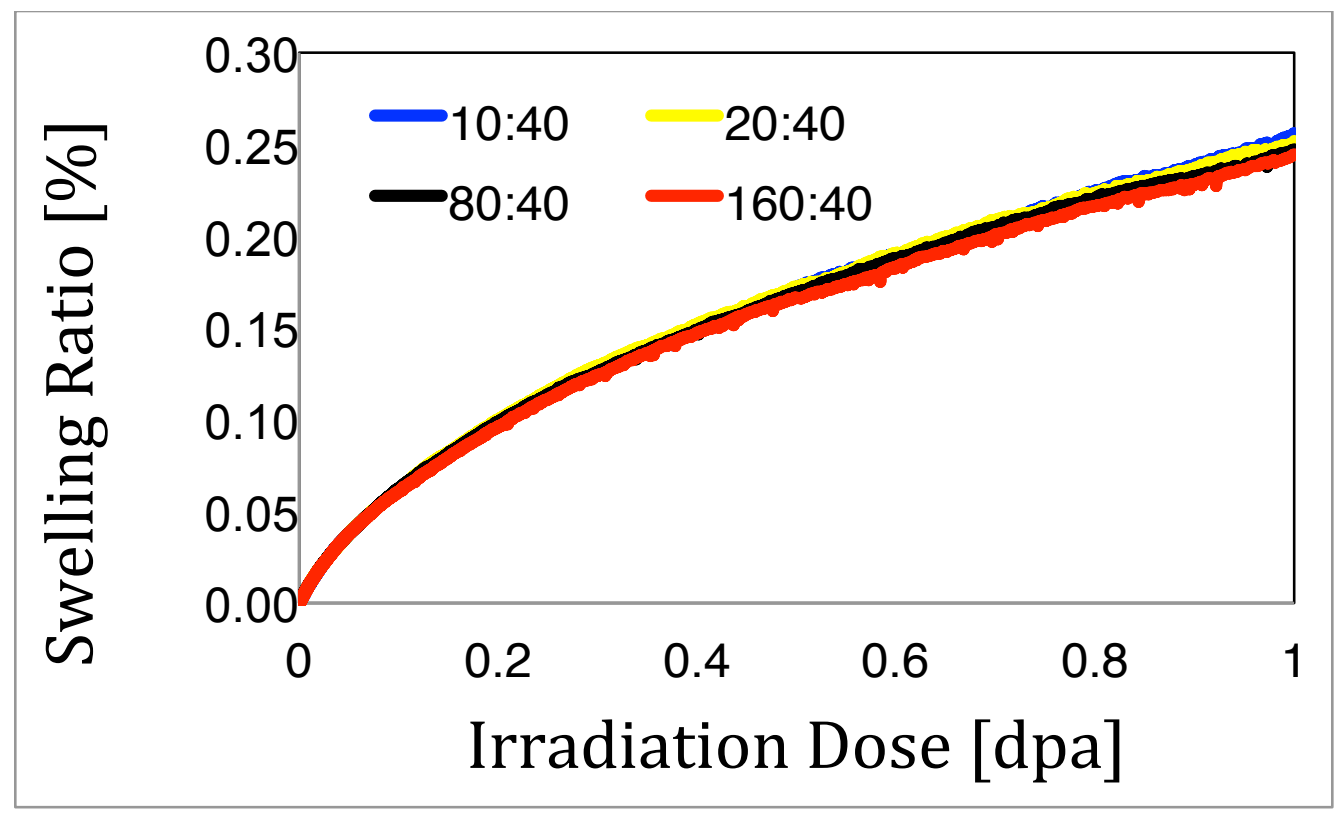

Figure 19: Effect on the swelling ration of the relative amount of $\mathrm{He}$ to $\mathrm{H}$ injected in the system.

We have also looked at the effect on swelling of the He-to-H insertion ratio. This is what is plotted in Figure 19 in terms of atomic parts per million per dpa for each species. Again, the differences are not remarkable, although clearly the higher the content of $\mathrm{He}$ relative to $\mathrm{H}$, the lower the swelling. If one looks at the evolution with dose of the average bubble size with this ratio, shown in Figure 20, this trend is maintained, although it appears that there exists a threshold He-to-H level beyond which the bubble size does no longer change. This is the case for rations of 80:40 and 160:40, where the average diameter saturates at about $1.2 \mathrm{~nm}$, down from $1.8 \mathrm{~nm}$ at the fusion ratio of 10:40.

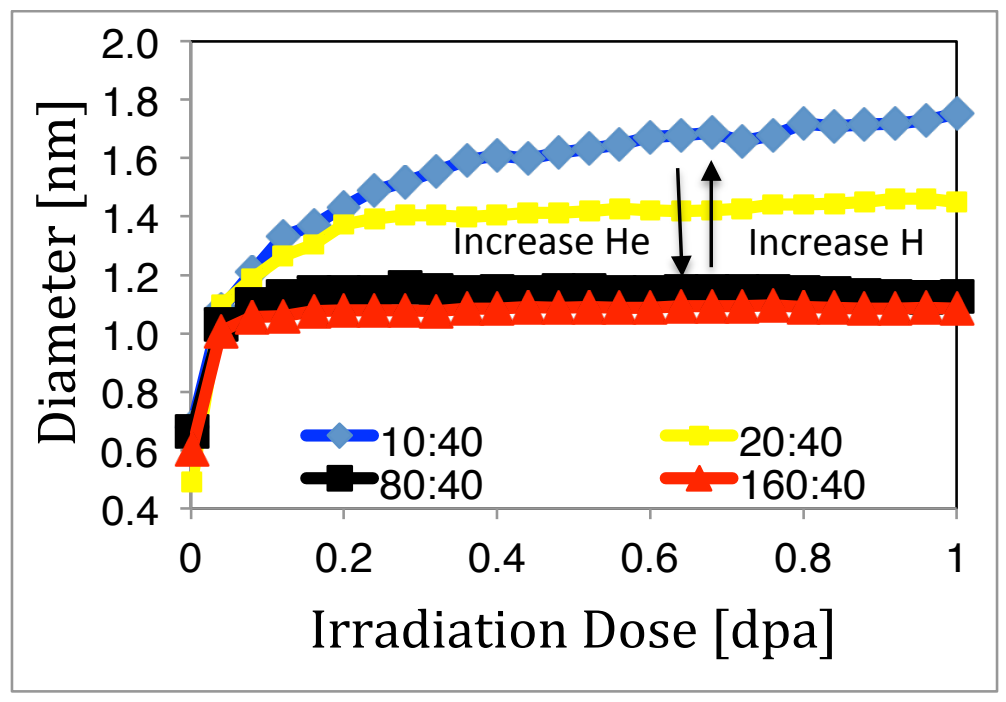

Figure 20: Evolution of the average bubble diameter with dose at $743 \mathrm{~K}$ as function of the He-to-H ratio.

Finally, we study the synergistic effect for the model of damage $/ \mathrm{He} / \mathrm{H}$ interaction described here. To this end, we plot in Figure 21 the average bubble size from three different simulations: (i) dual 
ion beam exposure with self-ions and $\mathrm{H}$ ions, (ii) dual ion beam exposure with self-ions and $\mathrm{He}$, (iii) triple ion beam exposure with self-ions, He and $\mathrm{H}$ ions. Clearly, the triple beam case results in the largest bubbles (in the form of triple clusters).

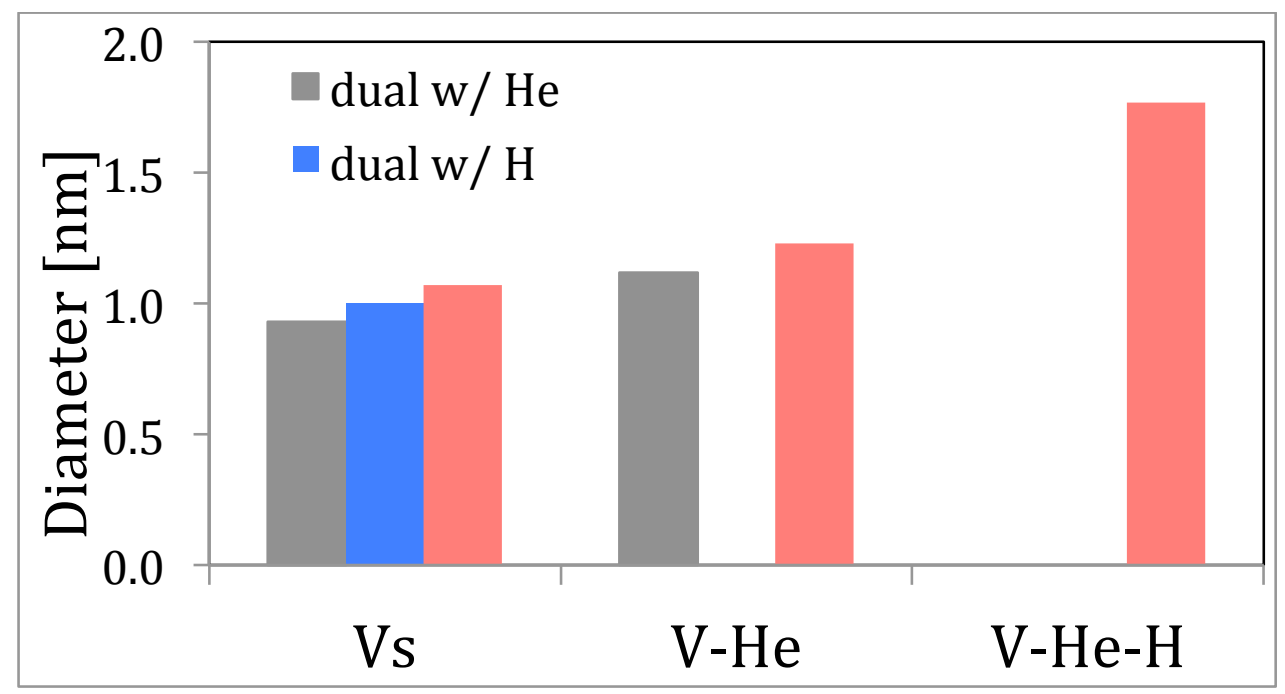

Figure 21: Average bubble diameter after $1 \mathrm{dpa}$ of irradiation at $743 \mathrm{~K}$ under dual and triple ion-beam irradiation conditions.

\section{Discussion and Conclusions}

\subsection{Where are we in terms of understanding?}

As expressed above, the evidence regarding damage $/ \mathrm{He} / \mathrm{H}$ interactions -both from experimental and computational sources- available to build a robust model of synergistic effects is insufficient at best, and often contradictory. At present, the experimental data collected over the last few decades provides a global picture of $\mathrm{He} / \mathrm{H}$ effects, where integrated quantities -e.g. swelling, or bubble density- are deconstructed to rationalize the observations in terms of microscopic mechanisms. Conversely, the majority of modeling focuses primarily on the atomistic scale, providing detailed mechanistic information but often with no clear connection to the observed microstructure. The fact that some times these two sources of data appear contradictory may mean that the connection between the spatial and temporal scales has not been properly established, just as much as it may mean that our interpretation of the data, which was used to set the modeling guidelines, is incorrect. In either case, this points to the need for more experiments and modeling, as discussed below.

\subsection{The need for more experiments and a fusion materials test facility}

The nuclear degradation of structural materials in a fusion demonstration reactor will require preconstruction testing under neutron radiation conditions currently unavailable and for some time into the future. Simultaneous irradiation using three ion beams can emulate the fusion neutron environment and provide valuable information obtainable in no other way.

Today, the neutron radiation platforms that are available are thermal and fast materials test reactors, and spallation sources. These provide radiation environments that have similarities to but are not identical with that expected from a fusion source, specifically $(\sim 10 \mathrm{He}$ appm/dpa) and $(\sim 40 \mathrm{H}$ appm/dpa). In fission reactors it has been demonstrated that the appropriate ratio of $\mathrm{He}$ to neutron initiated displacement damage can be simulated over limited depths of materials by making use of implantation with $(n, \alpha)$ reactions from carefully chosen coatings. In spallation sources, the He/dpa and $\mathrm{H} / \mathrm{dpa}$ ratios are significantly greater by a factor of 10 or more than what 
is expected for first wall and blanket structural components. However, the dose rates in terms of dpa and the energy distribution of the primary knock-on atom recoils is very similar to what would be expected in a fusion neutron source but with a high-energy tail. In contrast MSIB triple-ion-beam experiments can emulate the production of displacement damage and the simultaneous production of helium and/or hydrogen over a broad range of doses, dose rates, temperature, mechanical, and chemical conditions. This flexibility provides an attractive experimental platform for discovering and understanding the variety of damage accumulation mechanisms that might be operative and by informing modeling methods can lead to a qualified prediction of material performance under fusion conditions.. However, in order to significantly reduce the risk and uncertainty associated with a choice of material we will require a materials testing platform based on an intense $14 \mathrm{MeV}$ source of neutrons-unfortunately this is not available today, nor will it be available for some time.

One can reasonably expect that a demonstration fusion reactor will be constructed from a variant of a reduced activation ferritic, or ferittic-martensitic steel (RAF/M steel). Thus, the question is: what are the scientific issues that must be resolved early-on such that further research and development associated with the RAF/M steels can proceed based on sound scientific knowledge? Many of these questions, both known and unknown can be investigated or discovered with the carefully combined use of the results from MSIB experiments informing advanced modeling techniques. The first of such triple beam experiments have been performed for $\mathrm{F} 82 \mathrm{H}$ steel at $50 \mathrm{dpa}, 470^{\circ} \mathrm{C}$, and a dose rate of $1.6 \times 10^{-3} \mathrm{dpa} / \mathrm{s}$ with startling results - the discovery of a hydrogen synergistic effect leading to significantly increased volumetric changes compared to an equivalent irradiation without $\mathrm{H}$ but with $\mathrm{He}$ and dpa damage at the same doses, dose rates. This observation raises several interrelated and important basic research questions:

1. How does this vary as one goes to lower dose rates such as in the fusion environment? What is the temperature window and what controls it, and how does it vary from one material to another?

2. What metallurgical treatments if any can be used to mitigate this excess swelling, e.g., cold working, heat treatments, additives, etc.?

Because ion beam experiments are performed at dpa rates that are 2 to 3 orders of magnitude greater than those that will be encountered in a fusion environment, there remains the reasonable question as regards dose rate effects. While carefully designed triple beam experiments can discover important key mechanisms it is not always clear if these mechanisms are relevant to the much lower dose rate (lower dpa rate and lower transmutation rate) encountered in a fusion reactor. We are not helpless experimentally because we can vary three important parameters in ion-beam irradiation experiments: dose, dose-rate, and temperature. Variations in the evolved microstructure associated with these three variables will lead to improved simulation and modeling because this parametric space will bracket the observed microstructural features. Additionally, by making comparisons with experiments carried out using the existing neutron platforms (fission and spallation) we can further create the linkages that can span the wide ratescale from ions to neutrons.

The excess swelling observed for fusion conditions with triple-beams appears to suggest a swelling temperature that is material dependent but loosely in the range 400 to $550{ }^{\circ} \mathrm{C}$. How does this peak or window for excess swelling vary with material and material microstructure or refining elements? Ultimately, if such synergistic effects extend to the fusion neutron case, it will be important to perform research on all candidate materials to determine the temperature dependence of the excess swelling. Similarly, will sequestering of helium in ODS and nanodispersed alloys or some other mechanism associated with the nano-particles suppress the 
observed hydrogen synergy, or will new phenomena become apparent as a result of the radiation effects associated with the nano-dispersed oxide particles such as we have suggested ealier? Without either experimentation or an understanding of the underlying mechanism(s) such a question will remain unanswered. Carefully designed triple beam experiments can accelerate our understanding of the role of hydrogen in radiation damage accumulation for fusion materials. Ideally, such triple beam studies, coupled with comparisons of corresponding spallation studies, would be undertaken early in the on-going program of materials research for fusion energy so as to answer the underlying scientific questions and retire the risk associated with hydrogen produced in, or injected into structural elements of a fusion reactor.

\subsection{The need for more modeling}

As discussed above, modeling acts as a bridge between the current understanding of combined $\mathrm{dpa} / \mathrm{He} / \mathrm{H}$ effects - which derives primarily from ion-beam irradiation studies- and real (expected) fusion operation conditions. Evidently, modeling alone will not be sufficient to define materials design guidelines or set operability limits, but it can provide valuable insight into the processes leading to materials degradation in fusion environments, and thus help 'guide' design engineers or operation technicians. Currently, materials modeling cannot be faithfully achieved without following some kind of multiscale approach such that mechanistic information obtained from high fidelity models (with atomistic resolution) can be incorporated into scale-homogenized methods capable of reaching long length and time scales. It is fair to say that simulation of combined damage/He/H effects in F/M and -even- ferritic model alloys is still in its infancy, and much more effort must be devoted to studying the fundamental behavior of $\mathrm{He}$ and $\mathrm{H}$ atoms with point defects from an electronic structure, as well as a mechanical, standpoint. Particular emphasis must be put in looking at the possible chemistry of $\mathrm{He} / \mathrm{H} /$ alloy agglomerates, which can only be done via expensive DFT calculations. Only after these effects have been ascertained one can build with confidence an energetics database that can be then used in higher-level statistical methods such as rate theory and Monte Carlo. These latter methods are not without their own sets of challenges, most notably closing the time scale gap with real reactor conditions. The interest of these enhancements transcends of course the realm of fusion materials and is an active research topic in its own right. In any case, modeling will continue to play its bridging role and provide mechanistic insight so that scientists can have time window into true fusion reaction rates and conditions.

\section{Acknowledgments}

JM acknowledges support from DOE's Early Career Research Program. This work performed under the auspices of the U.S. Department of Energy by Lawrence Livermore National Laboratory under Contract DE-AC52-07NA27344. 


\section{References}

1 R. Bullough, report: "Factors involved in the use of vanadium alloys and ferritic steels for the ITER first wall/blanket and divertor", UKAEA FUS 554, EURATOM/UKAEA Fusion, June 2009

2 Calculations by Mark Gilbert, CCFE (2014)

3 G.R. Odette, M.J. Alinger, and B.D. Wirth, Annual Review of Materials Research 38: 471503 (2008)

4 R. L. Klueh, K. Ehrlich, F. Abe, Journal of Nuclear Materials 191-194 A: 116-124 (1992).

5 R. Bullough, report: "Factors involved in the use of vanadium alloys and ferritic steels for the ITER first wall/blanket and divertor", UKAEA FUS 554, EURATOM/UKAEA Fusion, June 2009

6 S.J. Zinkle, A. Möslang, T. Muroga, H. Tanagawa, Proceedings of the 24th IAEA Fusion Energy Conference, San Diego, USA, 8-13 October, 2012, OV/5-4

7 Gilbert M.R. and Sublet J.-Ch. Nucl. Fusion 51: 043005 (2011).

8 M.R. Gilbert, S.L. Dudarev, S. Zheng, L.W. Packer and J.-Ch. Sublet, Nucl. Fusion 52 (2012) 083019 .

9 F.A. Garner, E.P. Simonen, B.M. Oliver, L.R. Greenwood, M.L. Grossbeck, W.G. Wolfer , P.M. Scott , Journal of Nuclear Materials 356 (2006) 122-135

10 S. J. Zinkle and J. T. Busby, Materials Today 12 (2009) 12-19

11 F. Kano, Y. Arai, K. Fukuya, N. Sekimura and S. Ishino. J. Nucl. Mater 203 (1993) 151

12 K. Farrell and E. H. Lee, Radiation-Induced Changes in Microstructure: I, STP 955, American Society For Testing and Materials, Philadelphia, 1987, pp. 498-507.

13 F. A. Garner and L. R. Greenwood, Radiation Effects and Defects in Solids, 144 (1998) 251283.

14 Garner FA, BM Oliver, LR Greenwood, DJ Edwards, SM Bruemmer, and ML Grossbeck. 2002. "Generation and Retention of Helium and Hydrogen in Austenitic Steels Irradiated in a Variety of LWR and Test Reactor Spectral Environments." In Fusion Materials: Semi-Annual Progress Report Ending June 30, 2001, vol. 30, pp. 127-147. DOE Office of Fusion Energy Sciences, Washington DC.

15 Bo Yao, Danny J. Edwards, Richard J. Kurtz, G. Robert Odette and Takuya Yamamoto, Journal of Electron Microscopy 0(0): 1-8 (2012); X Hu, D Xu, BD Wirth, Journal of Nuclear Materials 442 (2013), S649-S654;

16 Myers, S. M., Besenbacher, F., and Bottiger, J., Applied Physics Letters 39: 450 (1981)

17 E. Wakai, T. Sawai, K. Furuya, A. Naito, T. Aruga, K. Kikuchi, S. Yamashita, S. Ohnuki, S. Yamamoto, H. Naramoto, S. Jistukawa. J. Nucl. Mater. 307-311 (2002) 278-282.

18 E. Wakai, K. Kikuchi, S. Yamamoto, T. Aruga , M. Ando, H. Tanigawa, T. Taguchi, T. Sawai, K. Oka, S. Ohnuki, J. Nucl. Mater., 318 (2003) 267-273

19 T. Tanaka, K. Oka, S. Ohnuki, S. Yamashita, T. Suda, S. Watanabe, E. Wakai, Journal of Nuclear Materials 329-333 (2004) 294-298

20 M. Ando, E. Wakai, T. Sawai, H. Tanigawa, K. Furuya, S. Jitsukawa, H. Takeuchi, K. Oka, 
S. Ohnuki, A. Kohyama, Journal of Nuclear Materials 329-333 (2004) 1137-1141.

21 E. Wakai, M. Ando, T. Sawai, K. Kikuchi, K. Furuya, M. Sato, K. Oka, S. Ohnuki, H. Tomita, T. Tomita, Y. Kato, F. Takada, Journal of Nuclear Materials 356 (2006) 95-104.

22 E. Wakai, M. Ando, T. Sawai, and S. Ohnuki, Materials Transactions, Vol. 48, No. 6 (2007) pp. 1427 to 1430

23 M. J. Fluss, L. L. Hsiung, J. Marian, Dual and triple ion-beam irradiations of Fe, F(Cr) and $\mathrm{Fe}(\mathrm{Cr})-\mathrm{ODS}$, Report: LLNL-TR-515275, 2011

24 T. R. Allen, J. Gan, J. I. Cole, S. Ukai, S. Shutthanandan, and S. Thevuthasan, The Stability of 9Cr-ODS Oxide Particles Under Heavy-Ion Irradiation, Nuclear Science And Engineering: 151, 305-312 (2005); J. Gan, T.R. Allen, R.C. Birtcher, S. Shutthanandan, and S. Thevuthasan, Radiation Effects on the Microstructure of a 9Cr-ODS Alloy, JOM (2008) 2428

25 S.V. Rogozhkin, A.A. Aleev, A.G. Zaluzhnyi, A.A. Nikitin, N.A. Iskandarov, P. Vladimirov, R. Lindau, A. Möslang, Journal of Nuclear Materials 409 (2011) 94-99

26 I. Monnet, P. Dubuisson, Y. Serruys, M.O. Ruault, O. Kaïtasov, B. Jouffrey, Journal of Nuclear Materials 335 (2004) 311-321.

27 T. Ishizaki, Q. Xu, T. Yoshiie, S. Nagata, T. Troev, J. Nucl. Mater. 307-311 (2002) 961-965

28 G.D. Tolstolutskaya, V.V. Ruzhytskiy, I.E. Kopanets, S.A. Karpov, V.V. Bryk, V.N. Voyevodin, F.A. Garner, J. Nucl. Mater., 356 (2006) 136-147

29 F.A Garner, B.M Oliver, L.R Greenwood, M.R James, P.D Ferguson, S.A Maloy, W.F Sommer, J. Nucl. Mater., 296 (2001) 66-82

30 S. Linderoth, A. V. Shishkin, Philos. Mag. A 55 (3) (1987) 291

31 V. V. Kirsanov and M. V. Musina, J. Nucl. Mater. 191-194 (1992) 1318-1322

32 E. Hayward, C. Deo, J. Phys.: Condens. Matter 24 (2012) 265402

33 C. J. Ortiz, R. Vila, J. M. Pruneda,arXiv:1205.6374v2 [cond-mat.mtrl-sci]

34 Jaime Marian, Vasily V. Bulatov, Journal of Nuclear Materials 415 (2011) 84-95 